\title{
Moving Bed Reactors: Challenges and Progress of Experimental and Theoretical Studies in a Century of Research
}

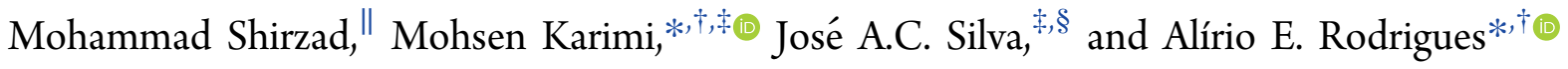 \\ ${ }^{\dagger}$ Laboratory of Separation and Reaction Engineering (LSRE), Associate Laboratory LSRE/LCM, Department of Chemical \\ Engineering, Faculty of Engineering, University of Porto, Rua Dr. Roberto Frias, S/N, 4099-002 Porto, Portugal \\ ${ }^{\ddagger}$ Grupo de Processos e Produtos Sustentáveis, Centro de Investigação de Montanha (CIMO), 5300-253 Bragança, Portugal \\ ${ }^{\S}$ Department of Chemical and Biological Technology, Polytechnic Institute of Bragança, Campus de Santa Apolonia, 5300-857 \\ Bragança, Portugal \\ "School of Chemical Engineering, College of Engineering, University of Tehran, P.O. Box 11365-4563, Enghelab, Tehran \\ 11365-4563, Iran
}

\section{Supporting Information}

\begin{abstract}
Moving bed reactors (MBRs) have been proposed as a sign of significant progress in the reaction engineering area for performance improving and energy saving. Since their advent in 1890, the MBRs have attracted a wide acceptance in different industries, while they were first developed for the drying industries. The progress that this technology has made during its evolution led to the introduction of these reactors as a pioneer strategy in other industries including petroleum, petrochemical, pyrolysis, and biomass industries. In the traditional reaction systems, the process performance decreases during the operational conditions, while MBRs have obviated this drawback by having an all-around permanent acceptable efficiency. In this context, the present work provides an overview on the evolution of MBRs by investigating the main experimental and theoretical studies. In this way, the experimental studies have typically taken into account operational conditions and production rates of different products, while in the theoretical research, modeling, and simulation of conventional processes, the evaluation of novel configurations and the optimization techniques have been investigated. In the end, some suggestions are proposed to modify the traditional MBRs as helpful ideas for further studies.
\end{abstract}

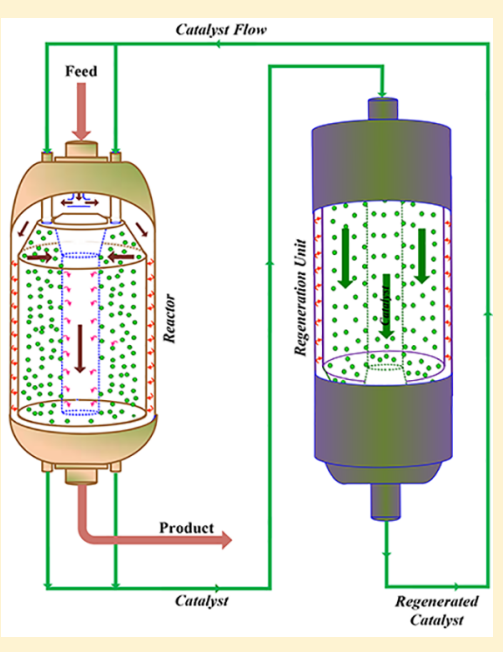

\section{INTRODUCTION}

Chemical Engineering is responsible for the design and operation of processes, which produce a wide range of products

Table 1. Main Factors in Catalyst Deactivation in Different Chemical Processes

\begin{tabular}{|c|c|c|}
\hline parameters & type & ref \\
\hline $\begin{array}{l}\text { metal } \\
\text { impurities }\end{array}$ & chemical & in 2018 , Gavrilovic et al. ${ }^{35}$ \\
\hline $\begin{array}{l}\text { thermal } \\
\text { instability }\end{array}$ & thermal & $\begin{array}{l}\text { in 2014, Paasikallio et al.; } \\
\text { in 2018, Rodriguez et al. }\end{array}$ \\
\hline $\begin{array}{l}\text { carbon } \\
\text { deposit }\end{array}$ & mechanical & $\begin{array}{l}\text { in 2018, Rodriguez et al.; in 2014, Argyle et al.; } \\
\text { in 2015, Rytter et al. }{ }^{37-39}\end{array}$ \\
\hline fouling & mechanical & in 2015, Argyle et al.; in 2015, Lang et al. ${ }^{34,40}$ \\
\hline attrition & mechanical & $\begin{array}{l}\text { in } 2015 \text {, Argyle et al.; } \\
\text { in } 2016 \text {, Satyanarayana et al. }\end{array}$ \\
\hline crushing & mechanical & $\begin{array}{l}\text { in } 2015 \text {, Argyle et al.; } \\
\text { in } 2016 \text {, Satyanarayana et al. }\end{array}$ \\
\hline $\begin{array}{l}\text { loss of } \\
\text { metallic- } \\
\text { basis }\end{array}$ & mechanical & $\begin{array}{l}\text { in } 2018, \text { Braz et al.; } \\
\text { in } 2018 \text {, Megias-Sayago et al. }{ }^{42,43}\end{array}$ \\
\hline poisoning & chemical & $\begin{array}{l}\text { in 2015, Argyle et al.; in 2014, Argyle et al.; } \\
\text { in 2015, Lang et al. }\end{array}$ \\
\hline
\end{tabular}

in different areas. Accordingly, the entirety of the process from the raw materials until the final products should be considered and evaluated, simultaneously, while the chemical reactors play a key role in all chemical plants. ${ }^{1,2}$ In the reactors, multiple reactions occur, and usually different catalysts are required to achieve the desired rates and selectivities. These factors that determine the production rate have a significant impact on the economics of the chemical plants, specifying at the same time the amount of waste products, which can have a major effect on the environment. ${ }^{1}$ Thus, the design, scale-up, and performance improvement of chemical reactors have been extensively investigated by many researchers in the past decades.

1.1. What Is a Moving Bed Reactor? Moving bed technology (MBT) has been introduced for more than a half century $^{3-8}$ and was developed by investigating the steady-state processes 9,3 and modeling analysis through mathematical models. ${ }^{10-12}$ The first MBT patent was published in 1890 by

Received: February 28, 2019

Revised: $\quad$ May 5, 2019

Accepted: May 9, 2019

Published: May 9, 2019 


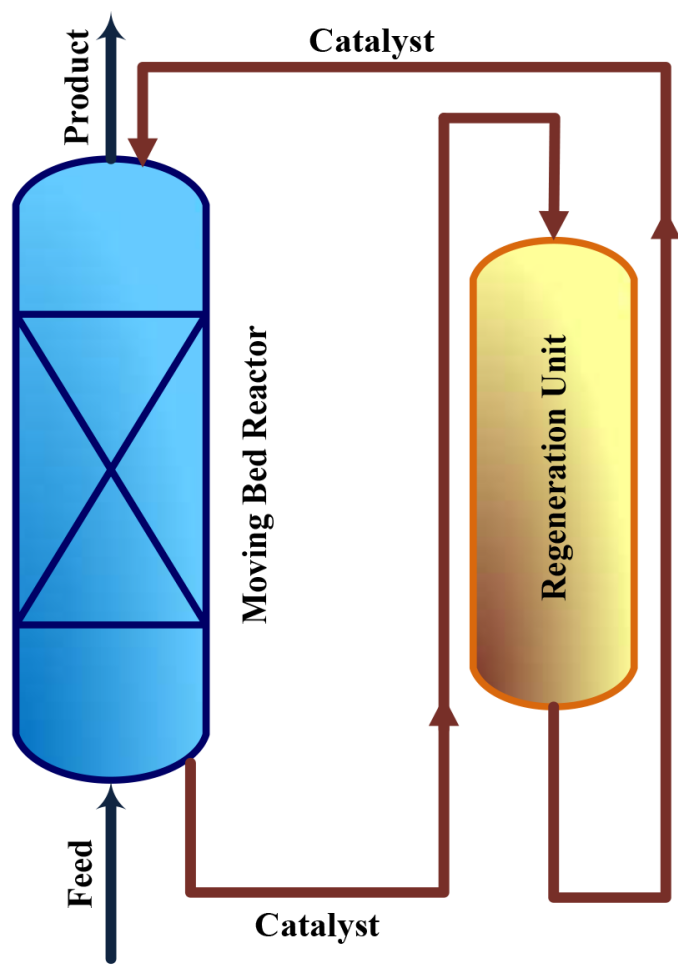

Figure 1. Block diagram of a moving bed reactor connected to a regeneration unit.

Andrews. ${ }^{13}$ There was a concern about coating and fouling the gas purifying materials for products or byproducts through the separation process. Consequently, the purifier materials became inert, and no separation occurred after a while. This problem was solved via a separation process by proposing moving bed reactors (MBRs). ${ }^{13}$ An MBR is a catalytic reactor in which a layer of catalysts in the form of granules is moved through the reaction bed and regenerated in the regeneration unit, continuously. Since the advent of MBT, it has attracted significant attention in different areas, including the separation of chemical compounds, ${ }^{14,15}$ the methane combustion application, ${ }^{16}$ the recuperation of petrochemical processes, drying of grains and seeds, and also the organic matter elimination from the effluents, ${ }^{14}$ etc. Finally, some new potential applications in bioprocesses have been studied by MBT, ${ }^{17}$ especially in biofilm processes for municipal and industrial wastewater treatment. ${ }^{18-20}$ On the other hand, the kinetic theory of the granular flows in MBRs has been considered in some engineering systems like the steel production industries from iron ore, some advanced manufacturing products, ${ }^{21,22}$ and finally in biomass processes as an ecofriendly energy generation technology. ${ }^{3}$ The MBRs have main benefits including low energy consumption and pressure drop, increasing the net profit of the plant by reducing the maintenance costs, ${ }^{23}$ improving the process performance, ${ }^{14}$ and also enhancing the contact surface of gassolid systems. ${ }^{17}$

Typically, chemical reactions of different processes ${ }^{24}$ take place in the catalytic beds, ${ }^{25}$ which can be classified in three main categories $^{26}$ including fixed bed, fluidized bed, and moving bed. $^{27-29}$ In the petrochemical industries, fixed bed reactors are more common for light petroleum cuts with less than $250 \mathrm{ppm}$ metal impurities treating ${ }^{29}$ or hydration and dehydration reactions, ${ }^{30,31}$ while the MBR is considered for treating the heavy or light petroleum cuts with more than $250 \mathrm{ppm}$ metal impurities. On the other hand, the rotating bed reactors immobilize the solid phase (catalysts) in a porous chamber, which spins to maximize the axial mixing and convective transport. ${ }^{32}$ One of the main drawbacks of rotating reactors is the influence of the shear and/or the bubble formation in the chamber. ${ }^{33}$ Through the chemical reactions, on the basis of the scope of the process, different types of materials are produced, some of which may have adverse effects on the catalyst performance. The main agents of the catalyst deactivation ${ }^{34}$ are reported in Table 1.

In this way, the deactivated catalysts are required to be regenerated in the regeneration unit to operate as fresh catalysts in the chemical reactors. ${ }^{44}$ Specifically, the moving bed technology (MBT) is considered in the chemical and petrochemical industries as a continuous catalyst regeneration (CCR) unit ${ }^{44-46}$ to remove the coke deposited on the catalysts surfaces and regenerate them. In the CCR technology, the deactivated catalysts are withdrawn at the bottom of the reactor and introduced to the regeneration unit, which is connected to the top of the reactor. In the regeneration unit, the catalysts are regenerated by moving to the bottom of the unit in the gaseous media. Thereafter, they are introduced to the process as fresh catalysts. This procedure is continued, consistently, with a low pressure drop and energy consumption. ${ }^{45}$ Thus, the MBRs have the advantages of higher equilibrium yield ${ }^{47}$ and performance ${ }^{48}$ as compared to other processes.

In addition to the chemical and petrochemical industries, MBT has attracted much attention in other industries including bioethanol production, ${ }^{49}$ hydrogen production, ${ }^{50}$ drying, ${ }^{51}$ gas separation, ${ }^{52}$ and membrane bioreactors, ${ }^{53}$ etc. It is worth mentioning that the application of the MBT is at the developing step in these industries, while in the chemical and petrochemical processes it is a mature, reliable, and efficient strategy to control and manage the coke formation and pressure drop. ${ }^{54}$ On the other hand, CCR technology is applied in many processes such as biomass ${ }^{36}$ and Fischer-Tropsch, ${ }^{39}$ as a vital factor in having a high production rate at constant operational conditions. ${ }^{55}$ In this way, to maintain the yield and efficiency of the process as high as possible, which is directly influenced by the catalyst activity, it is required to regenerate the deactivated catalysts, continuously. ${ }^{30}$ The simple schematic of CCR by using MBT is presented in Figure 1.

It is worth mentioning that, in the literature, there are two types of moving bed reactors including the moving bed biofilm reactor $^{56-61}$ and chemical moving bed reactor. ${ }^{16,62-65}$ The moving bed biofilm reactor is employed for municipal and industrial wastewater treatment. ${ }^{60,66}$ This technology can improve the performance of the process by reducing the size of reactors compared with the conventional ones. ${ }^{67,68}$ On the other hand, it should be considered that the simulated moving bed reactor (SMBR) technology ${ }^{69-73}$ is a multifunctional reactor in which the chemical and separation reactions take place simultaneously, in a fixed bed reactor for adsorption processes. $^{74,75}$

1.2. Objective. In this study, the concept of the chemical moving bed reactors has been extensively investigated and reviewed from the advent of this technology until now; this, to the best of our knowledge, is the first review paper in this area. To this goal, all studies are classified in two main classes including (i) experimental studies and (ii) theoretical studies. Then, the accomplished works are defined as subsubjects in these areas. 


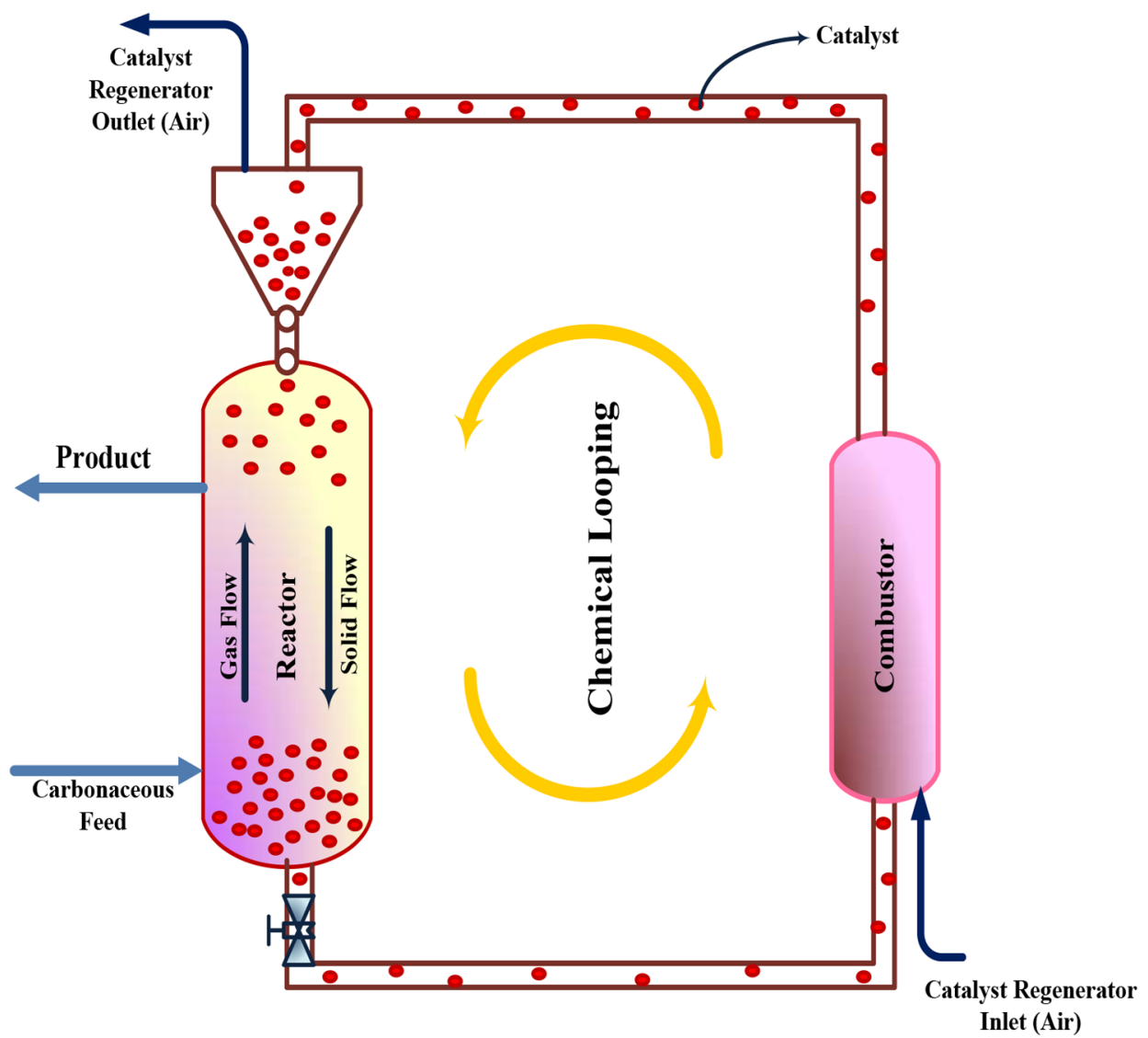

Figure 2. Schematic of chemical looping combustion.

Table 2. Different Types of Chemical Looping Processes

\begin{tabular}{|c|c|c|c|}
\hline technologies & feed & product & ref \\
\hline $\begin{array}{l}\text { chemical looping } \\
\text { gasification }\end{array}$ & coal & $\mathrm{H}_{2} / \mathrm{CO} / \mathrm{H}_{2} \mathrm{~S} / \mathrm{COS} /$ liquid product & in $2010, \mathrm{Li}$ et al.; in 2014 , Luo et al. ${ }^{82,83}$ \\
\hline \multirow[t]{2}{*}{$\begin{array}{l}\text { chemical looping } \\
\text { combustion }\end{array}$} & gaseous fuel & $\mathrm{H}_{2} \mathrm{O} / \mathrm{CO}_{2} /$ heat & $\begin{array}{l}\text { in 2012, Adanez et al.; in 2014, Chiu et al.; in 2015, Zeng et al.; } \\
\text { in 2013, Hong et al. }\end{array}$ \\
\hline & solid fuels & $\mathrm{H}_{2} \mathrm{O} / \mathrm{CO}_{2} /$ heat & $\begin{array}{l}\text { in 2012, Adanez et al.; in 2014, Chiu et al.; in 2015, Zeng et al.; in 2013, Hong et al.; } \\
\text { in 2015, Wu et al. }\end{array}$ \\
\hline $\begin{array}{l}\text { chemical looping } \\
\text { reforming }\end{array}$ & hydrocarbons & $\mathrm{H}_{2} / \mathrm{CO} / \mathrm{CO}_{2} /$ heat & in 2012, Adanez et al.; in 2014, Dou et al.; in 2012, Kang et al. ${ }^{84,89,90}$ \\
\hline $\begin{array}{l}\text { syngas chemical } \\
\text { looping }\end{array}$ & methane & $\mathrm{H}_{2} \mathrm{O} / \mathrm{CO}_{2} / \mathrm{H}_{2} /$ heat & in 2013, Tong et al. $^{91}$ \\
\hline
\end{tabular}

\section{EXPERIMENTAL STUDIES}

2.1. Chemical Looping Combustion. The increasing rate of fossil fuels consumption has contributed to the production of a huge volume of $\mathrm{CO}_{2}$, which adversely affects the environment and, consequently, the public health. ${ }^{76}$ In conventional power plants, there is not too much consideration for $\mathrm{CO}_{2}$ capture, ${ }^{77,78}$ but in recent years, many researchers have focused on developing novel configurations to improve the performance of available processes, based on the carbon capture and storage (CCS) strategy, to modify the energy consumption and reduce the $\mathrm{CO}_{2}$ emissions, simultaneously. ${ }^{.9}$ Chemical looping (CL) is a cyclic process in which the $\mathrm{CO}_{2}$ is separated with minimum consumption of the energy as well as high energy conversion in the process. ${ }^{76}$ Figure 2 shows a schematic of the chemical looping process integrated with MBT. Actually, in this process, the main products and carbon dioxide are produced in two separated reactors, which reduces the cost of $\mathrm{CO}_{2}$ separation and the purity of the obtained products. ${ }^{80}$ Furthermore, the integrated moving bed configuration regenerates the deactivated catalysts, continuously. ${ }^{81}$ Table 2 illustrates the different types of the chemical looping technologies, the carbonaceous feed, and different products of each chemical looping process.

The employed catalyst in this process is actually a chemical intermediate, which carries the required oxygen for the reactions. ${ }^{92}$ The oxygen carrier is reduced in the reactor by the carbonaceous feed to produce the main product and heat; after that, it is oxidized in the combustor. The loop is cycled continuously by using the MBT with a steady-state method. ${ }^{92}$ The oxygen carrier should possess some essential features including being low cost and ecofriendly and having a low tendency to agglomeration, high reactivity with the carbonaceous feed and oxygen, the ability to convert the carbonaceous feed to the products, low attrition, as well as a negligible fragmentation tendency. ${ }^{93}$

Recently, scholars have developed the moving bed reactor concept integrated with chemical looping technology on the 


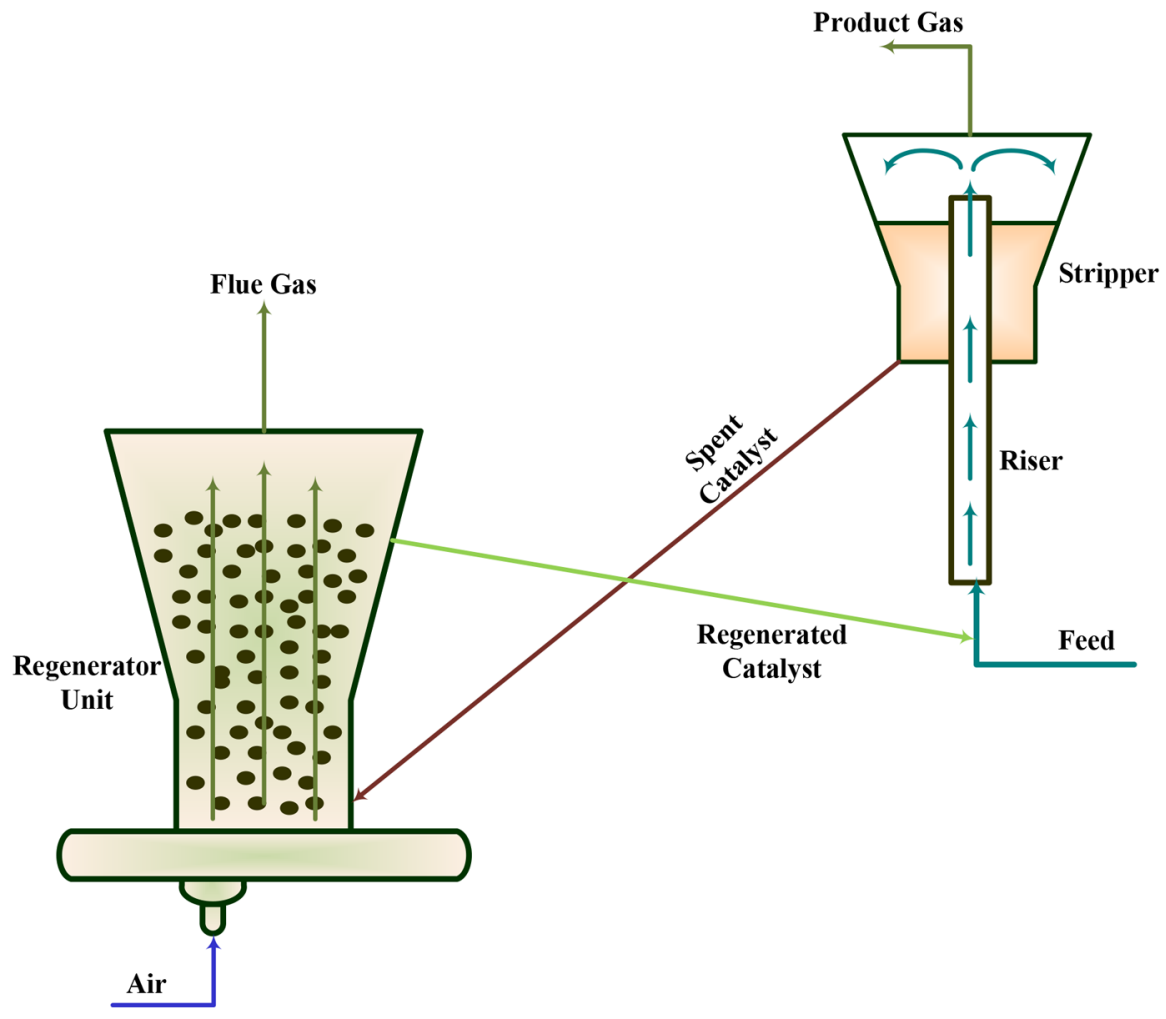

Figure 3. Schematic of the fluid catalytic cracking (FCC) process.

research and pilot scales, ${ }^{94,95}$ to produce $\mathrm{H}_{2}$ from methane ${ }^{94}$ and heavy liquid hydrocarbons as carbonaceous feeds. ${ }^{95}$ They have also focused on the effective parameters including the type of the oxygen carrier, ${ }^{94,96}$ the gas velocity in the moving bed configuration, and the type of the carbonaceous feed, ${ }^{95}$ by experimental studies ${ }^{94,95}$ as well as mathematical modeling. ${ }^{97}$ Furthermore, the study on the chemical looping combustion of the biomass integrated with MBT is ongoing by many researchers. ${ }^{88,98-100}$ It can be concluded from these studies that the CL technology integrated with MBT has high energy conversion potential and $\mathrm{CO}_{2}$ capture ability, which can be a promising concept in different areas. ${ }^{83,86,89,94,97,101-104}$

2.2. Fluid Catalytic Cracking. From around 70 years ago, fluid catalytic cracking (FCC) has been known as one of the key processes to obtain favorable fuels and different required products from the heavier fractions of the crude oil. ${ }^{105}$ In this way, the heavy oil, which is not as valuable as lighter cuts (middle distillates, diesel, gasoline, and even light olefins such as propylene), is processed and contributes as a significant commodity in the fuels market. ${ }^{106}$ In fact, the FCC process includes a fluidized reactor with a moving bed, in which the applied catalysts are continuously regenerated. ${ }^{107}$ The simple schematic of this process is illustrated in Figure 3.

One of the most noticeable experimental works in this area has been devoted to developing more efficient FCC catalysts. From 1960, employing different zeolites has been considered as a basic part of FCC studies, ${ }^{108}$ but the potential substitution for zeolites, ${ }^{109}$ increasing catalyst performance, ${ }^{110,111}$ catalyst modifications, ${ }^{112-114}$ and improving regeneration process ${ }^{115}$ have been extensively investigated in the past decades. On the other hand, the modification of the operational conditions of the FCC process, ${ }^{116}$ pilot-scale experiments, ${ }^{117}$ fault-detection of the industrial FCC units, ${ }^{118}$ etc. are the other favorable topics in the FCC field, which have been considered so far.

In addition, the combination of the FCC process with chemical looping combustion to reduce the $\mathrm{CO}_{2}$ emission through the process, ${ }^{119}$ the post-treatment of FCC products, ${ }^{120-123}$ biofeed synergistic effects on the heavy petrochemical feeds, ${ }^{124,125}$ simultaneous removal of catalyst particles from the FCC process, ${ }^{126}$ etc. are some of the other main studies, which have been considered to improve the performance and efficiency of this process. More details in this area can be found in the recent review papers, which have been published in Vogt and Weckhuysen, ${ }^{108}$ Otterstedt et al., ${ }^{127}$ and Akah. ${ }^{128}$

2.3. Pyrolysis. Pyrolysis is a process which employs the energy to decompose worthless materials to useful products. $^{80,81,129-132}$ Recently, the integration of the pyrolysis process with MBR technology has contributed to a more efficient process because of the heat transfer improvement ${ }^{133,134}$ as well as the continuous operational condition. ${ }^{134}$ To this goal, different heat carriers have been considered as mediums, which enhance the heat transfer rate and the process efficiency. ${ }^{135}$ In this way, sands, ${ }^{135,136}$ gaseous compounds like nitrogen, ${ }^{137}$ etc. have been considered as heating media. Also in some cases, a special MBR has been employed in which the bed is moved mechanically by a belt ${ }^{138}$ or a screw-type shaft ${ }^{134,139}$ without the heating media. ${ }^{140,141}$ Figure 4 shows two common types of MBR configurations in pyrolysis processes, schematically.

Lastly, the recycling of tires and plastics and their conversion into valuable fuels (e.g., fuel gas ${ }^{135}$ ) have been considered extensively, due to the significant environmental concerns in recent years. ${ }^{142-144}$ It is worth mentioning that the economic progress $^{135}$ and simplified processes ${ }^{142}$ have been developed in the pyrolysis studies, so far. However, more studies are required to be conducted in this area to achieve a lucrative technology. 

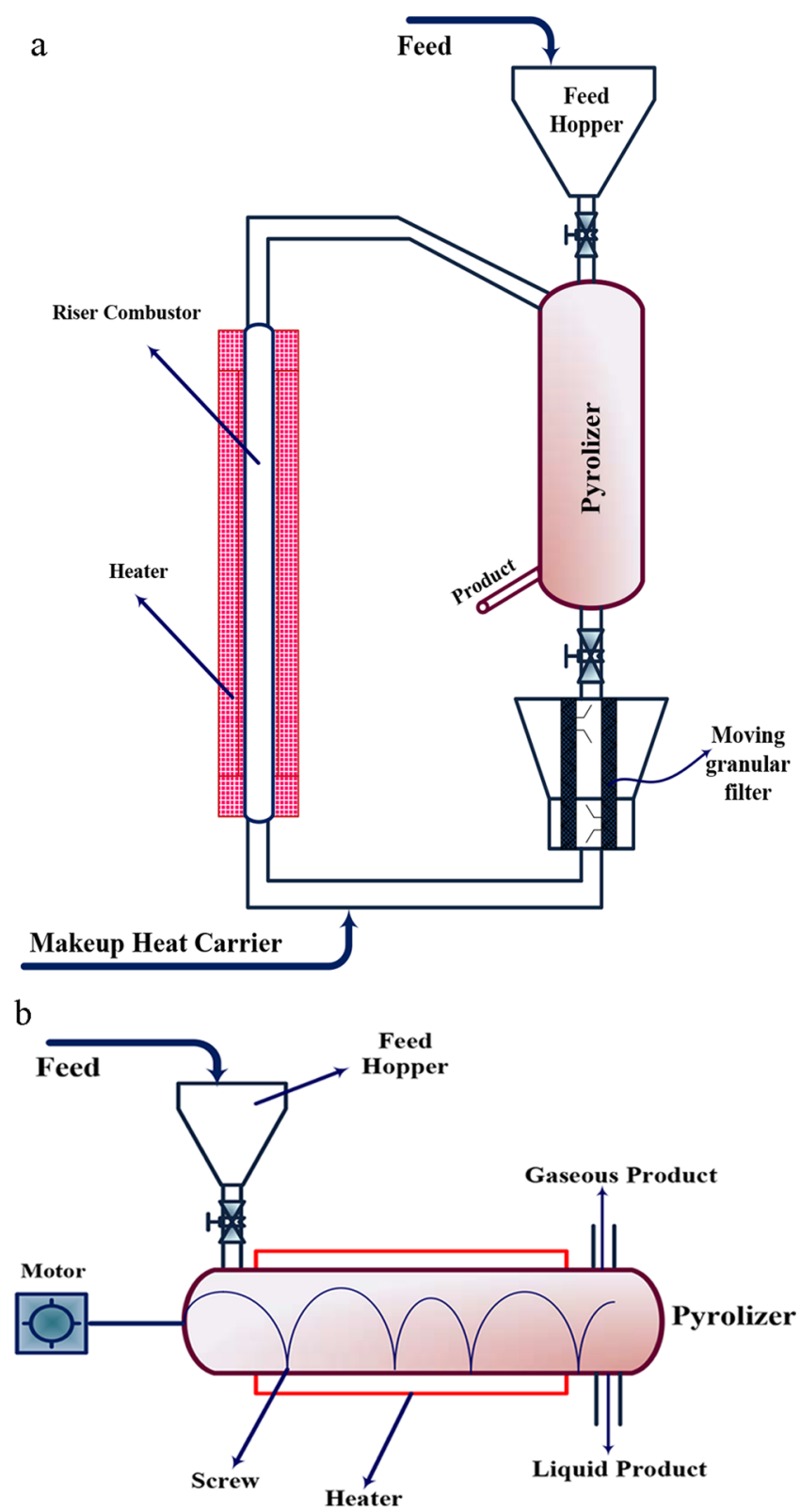

Figure 4. Schematic of the pyrolysis process with a moving bed configuration: (a) with a heating carrier and (b) without a heating carrier.

The pyrolysis of the oil shale has been recently studied in an innovative MBR. ${ }^{145,146}$ On the basis of the traditional oil shale pyrolysis system, the heat carrier passes through the solid oil shale to supply the required energy of the pyrolysis process. Hence, the gaseous products are blended with the heat carrier and make a homogeneous gaseous mixture. The separation of the gaseous mixture is a high-cost process and requires a large volume of the heat carrier, which adversely affects the purity of the pyrolysis products. On the other hand, this process is only able to pyrolyze the oil shale particles which have diameters with more than $15 \mathrm{~mm}^{145}$ and constitute around $15-20 \%$ of the total oil shale sample. These drawbacks of the traditional pyrolysis processes have forced researchers to develop an innovative strategy to overcome these limitations. In this way, the moving bed technology with a solid heat carrier (hot shale ash) has emerged due to the greater adaptability for treating the small size of the oil shale, higher oil shale yield, and the gas separation system in a simple way. ${ }^{145,147}$

Upon review, the recent studies on the pyrolysis process integrated with MBT support the idea that many researchers have employed this technology for converting biomass to syngas. ${ }^{148-152}$ The integrated pyrolysis technology with the moving bed configuration has eliminated the drying step, which is one of the main steps to obtain useful energy from biomass. ${ }^{151}$ The effects of parameters including temperature, ${ }^{148,150}$ type of the reactor, ${ }^{149}$ the heat carrier type, ${ }^{151}$ etc. have been investigated so far, while studies are ongoing in this area. Some of the main research about this process is presented in Table 3.

\section{THEORETICAL STUDIES}

In this chapter, a comprehensive review on the theoretical studies on the MBRs is presented. In this way, all main modeling studies on MBT have been investigated, while some of these studies are of mathematical modeling or process simulation on the available existing power plants, which have been accomplished on the basis of the industrial data. The other ones are hypothetical research, which have been proposed to improve the performance of the conventional MBRs, and these studies are in the developing step.

3.1. Modeled and Optimized Processes. Mathematical modeling and optimization of MBRs have been considered starting from around 40 years ago. ${ }^{153,154}$ Some modeling methods such as computational fluid dynamics (CFD) studies have just been applied to optimize the process. ${ }^{103,155,156}$ In the first studies, the composition and the temperature profile through the MBRs as well as the composition and the temperature profile at the effluent were considered as main factors in the MBT. ${ }^{153,154}$ They concluded that the analysis of the reactor effluent composition is not sufficient to validate the considered models; thus, the data of the moving bed is also required. ${ }^{153,157}$ Gradually, the modeling of the MBRs was developed, and more effective parameters were investigated including cocurrent/countercurrent configurations, ${ }^{158}$ the application of nanocatalysts, ${ }^{12}$ different types of the feed, ${ }^{159}$ radial flow pattern, ${ }^{160}$ the catalyst deactivation, ${ }^{161}$ the moving bed for the grain drying process, ${ }^{162}$ and the CVD coating of the fine particles. ${ }^{163}$ The process modeling has been conducted by considering the mass and energy balances, ${ }^{164}$ kinetics, ${ }^{165}$ the equilibrium, $^{90}$ and the physical properties. $^{90}$ The MBR configuration for three reactors is schematically demonstrated in Figure 5. It is worth mentioning that the number of reactors is changeable, and based on the type of the process, it can be one or more. Also, the flow patterns in the MBRs can be cocurrent $^{160,152}$ or countercurrent, ${ }^{159}$ which are demonstrated in Figure 6.

The modeling of MBRs has also been considered in the chemical looping process. ${ }^{90,97}$ The methane conversion in a countercurrent moving bed reactor was investigated by Ostace et al. $^{97}$ and Kang et al. ${ }^{90}$ The mass, energy, and pressure drop balances were applied to model the MBRs by assumptions of the radial $^{97}$ and plug ${ }^{90}$ flow patterns. On the other hand, the mathematical modeling and the optimization of MBRs integrated with chemical looping technology have been developed through the years. However, this new technology requires deeper studies to be known as a fully developed process. $^{86,166-168}$ The modeling of the biomass conversion to the valuable energy in the MBRs has also attracted much attention in recent years. $^{97,169,170}$ 
Table 3. Main Pyrolysis Studies with Moving Bed Technology

\begin{tabular}{|c|c|c|c|c|}
\hline $\begin{array}{l}\text { heat } \\
\text { carrier }\end{array}$ & kind of reactor & feed & products & ref \\
\hline sand & screw conveyor (moving bed) & waste plastic & fuel gas & in 2006 , Kodera et al. ${ }^{135}$ \\
\hline nitrogen & moving bed & Shenmu bituminous coal & gaseous hydrocarbons and $\mathrm{H}_{2}$ & in 2015 , Liang et al. ${ }^{137}$ \\
\hline steam & $\begin{array}{l}\text { belt conveyor (cross-flow moving } \\
\text { bed) }\end{array}$ & cellulose & char & in 2006, Yamaguchi et al. ${ }^{138}$ \\
\hline nitrogen & moving bed & waste tire & $\begin{array}{l}\text { BTX fraction, short aliphatic chain, and } \\
\text { limonene }\end{array}$ & in 2008, Aylon et al. ${ }^{134}$ \\
\hline nitrogen & moving bed & waste tire & gaseous products and solid residue & in 2010, Aylon et al. ${ }^{133}$ \\
\hline nitrogen & screw conveyor (moving bed) & waste tire & $\begin{array}{l}\text { low-molecular-weight products, liquids, or } \\
\text { gases }\end{array}$ & in 2010, Aylon et al. ${ }^{142}$ \\
\hline nitrogen & screw conveyor (moving bed) & inhomogeneous tire chips & gaseous products, pyrolytic oil, and char & in 2017, Rudniak and Machniewski ${ }^{144}$ \\
\hline nitrogen & moving bed & rapeseed stalk & hydrocarbons, $\mathrm{H}_{2}$, and oil & in 2017 , Gao et al. ${ }^{136}$ \\
\hline shale ash & moving bed with internals & oil shale & volatile products & in 2015, Lai et al.; in 2016, Lai et al. ${ }^{145,146}$ \\
\hline nitrogen & screw conveyor (moving bed) & sewage sludge & syngas & in 2018 , Zhu et al. ${ }^{149}$ \\
\hline nitrogen & screw conveyor (moving bed) & $\begin{array}{l}\text { wet sewage sludge with } \\
\text { sawdust }\end{array}$ & syngas & in 2018 , Yang et al. ${ }^{150}$ \\
\hline nitrogen & moving bed & biomass & gaseous products, bio-oil, and biochar & in 2018 , Zhang et al. ${ }^{148}$ \\
\hline
\end{tabular}

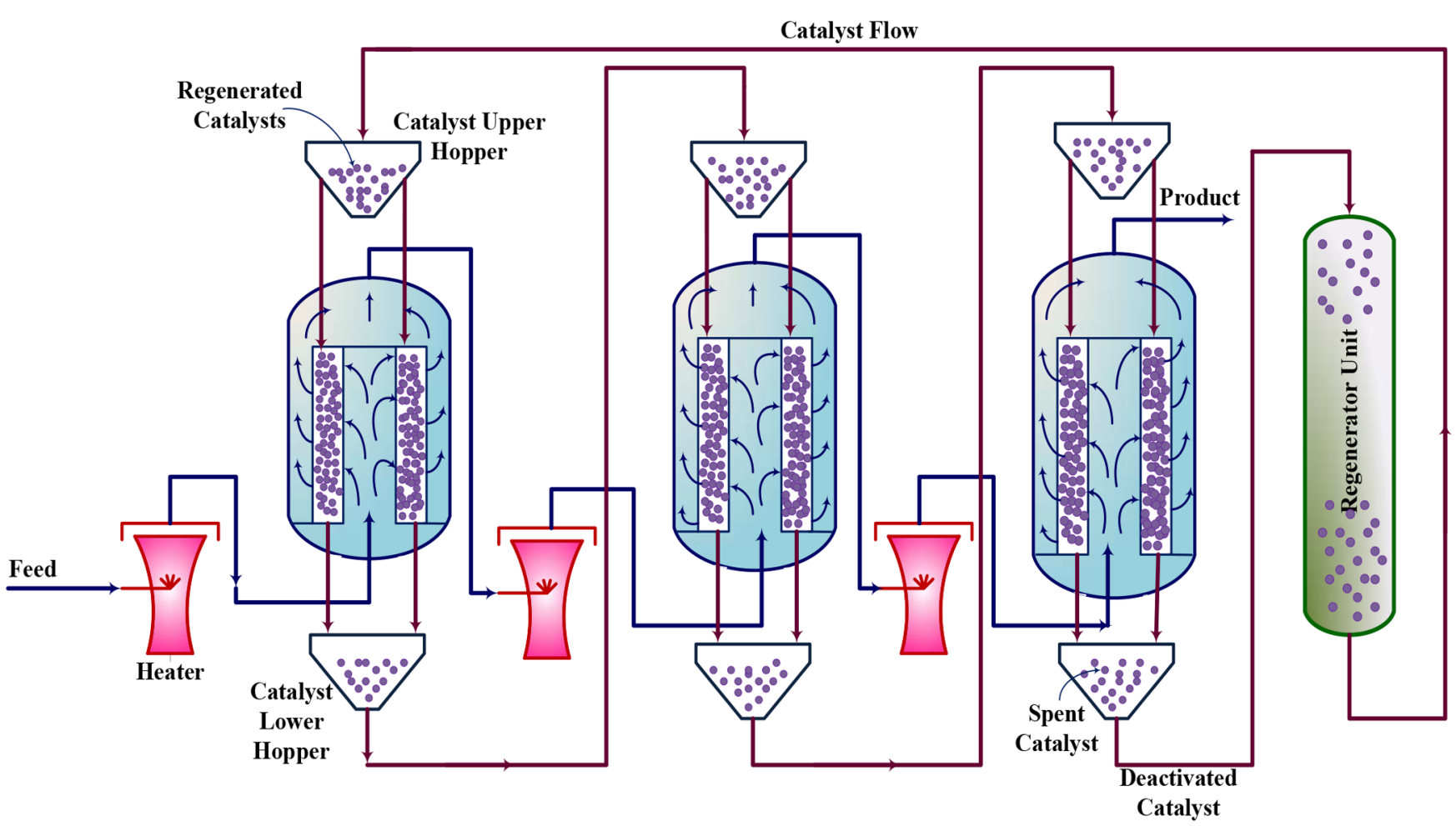

Figure 5. Schematic of a moving bed reactor configuration.

3.2. Gas-Solid Reactors. The main purpose of the gassolid moving bed reactors is related to some physical or chemical transformations in the moving solids; in the conventional MBRs the moving solid phase operates as a catalyst to accelerate the reaction rate in the gas phase. ${ }^{127,128}$ The gas-solid reactors can be categorized in two different regimes: (i) the axial flow regime (cocurrent and countercurrent) $)^{129}$ and (ii) the cross-flow pattern. ${ }^{171,174}$

The limitations of the gas-solid heat exchanging process convinced researchers to find an efficient strategy to enhance the heat transfer rate in this process. ${ }^{175}$ In this way, the gas-solid interaction in the MBRs was proposed to obviate the existing problem through the heat exchanging process. ${ }^{176}$ In the axial flow gas-solid moving bed configuration, the advantages of the countercurrent flow regime were applied through the direct reduction of the iron ore to the sponge iron by a reducing gas. In this process, MIDREX technology was propounded ${ }^{172}$ (as shown in Figure 7), in which the iron ores come downward while the reducing gas goes upward; ${ }^{174}$ meanwhile, the chemical transformation occurs. ${ }^{17}$

Several applications have been introduced for the cross-flow moving bed reactors such as dryers, ${ }^{162}$ the moving bed granular filter, ${ }^{178-181}$ and catalyst regeneration. Figure 8 shows the drying process for the cross-flow moving bed technology, schematically. After the successful application of the gas-solid moving bed in the MIDREX, researchers tried to employ gassolid moving bed technology as a chemical reaction bed. ${ }^{173,176,182}$

3.3. Fluid Catalytic Cracking. From the advent of the FCC process, many researchers have considered the theoretical 


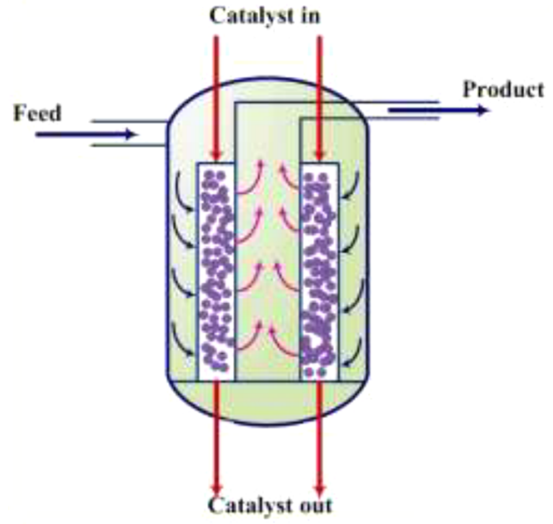

a

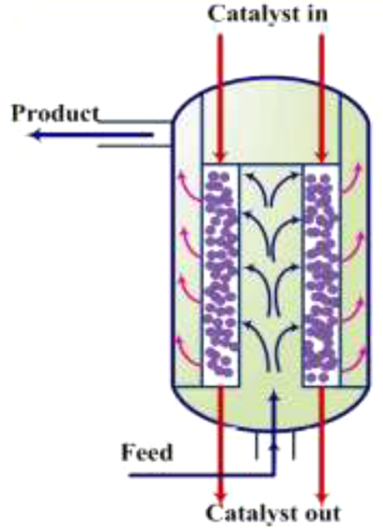

b

Figure 6. Flow types in the modeling of a moving bed: (a) concurrent and (b) countercurrent.

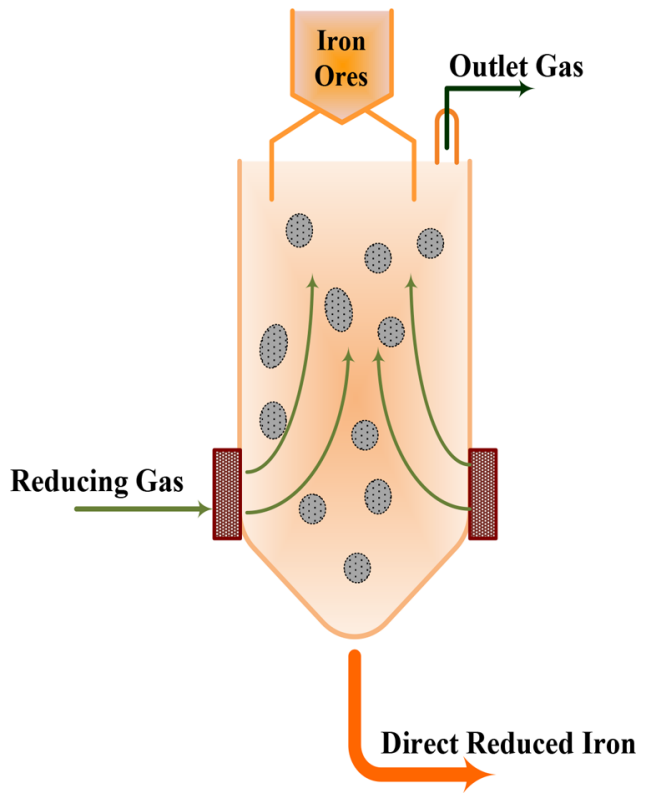

Figure 7. MIDREX technology to reduce iron ores to sponge iron in a moving bed reactor.

studies of this process by focusing on the mathematical modeling, process simulation, and the optimization of the key parameters. In fact, the FCC is a complex process which requires a precise and detailed description of models to cover the interaction of the model inputs and control the model outputs. ${ }^{183}$ In this context, various modeling procedures with different assumptions have been implemented. The lumpedkinetic assumption and proposing new methods with different lumped assumptions, ${ }^{184,185}$ a higher level of the lumped assumption, ${ }^{186,187}$ as well as a comparison of the different models ${ }^{184}$ are the most studied subjects in theoretical studies of the FCC process. The evaluation of the nonlinearity in this process and its effect on the model outputs was one of the first considered subjects in this area. ${ }^{188}$ Also, the mathematical modeling of the in-operation FCC plant was one of the other primary works. ${ }^{189}$ In addition, researchers have studied the hydrodynamics of the FCC process ${ }^{190,191}$ (intensifying the catalysts regeneration with baffles in the regenerator, ${ }^{192}$ the feed injection patterns and their effects on the FCC process performance, ${ }^{186}$ etc.) and the hydrodynamic optimization, ${ }^{193}$ which led to the economic improvement in the refineries.

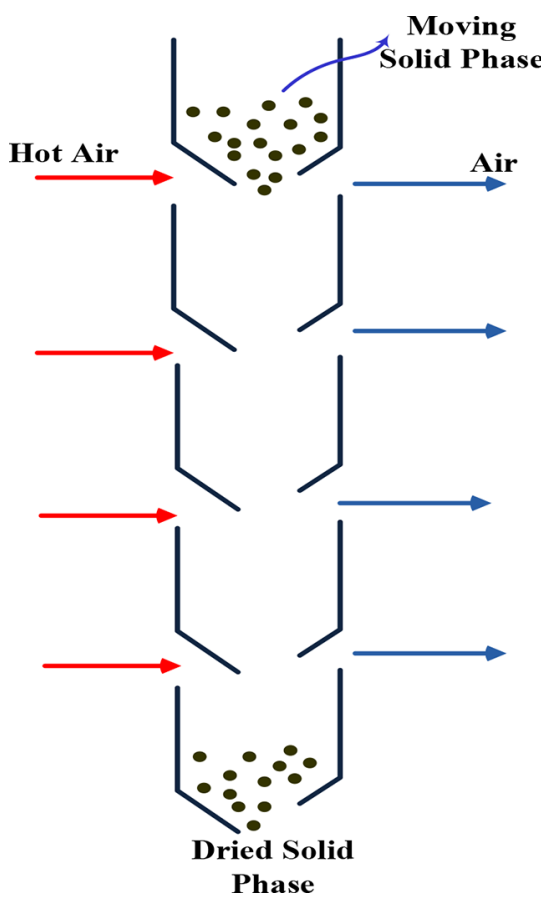

Figure 8. Schematic of a cross-flow moving bed dryer.

In recent years, the modification of the performance of the available FCC units has also attracted much attention. Thus, the optimal design of the FCC process for increasing the productivity, as one of the most important issues, has been considered. ${ }^{194}$ In this way, the combination of different processes $^{195}$ and different materials as the modifiers ${ }^{196,197}$ through the FCC has been investigated so far.

3.4. Naphtha Processes. The catalytic naphtha reforming is the main industrial process to obtain high-octane gasoline and aromatic hydrocarbons. ${ }^{198-200}$ UOP and Axens are two major licenses which represent the commercial reforming processes. According to UOP and Axens technologies, the feed should be hydrotreated to decrease the required catalysts for the reforming process. ${ }^{201}$ UOP technology, ${ }^{45}$ which employs stacked reactors, was introduced for the first time in 1971 (illustrated in Figure 9), while on the basis of Axens technology the MBRs are designed in a side by side configuration (as shown in Figure 7).

Catalytic naphtha reforming is a basic technology to produce high-octane reformate for gasoline blending. ${ }^{202}$ In this process, 


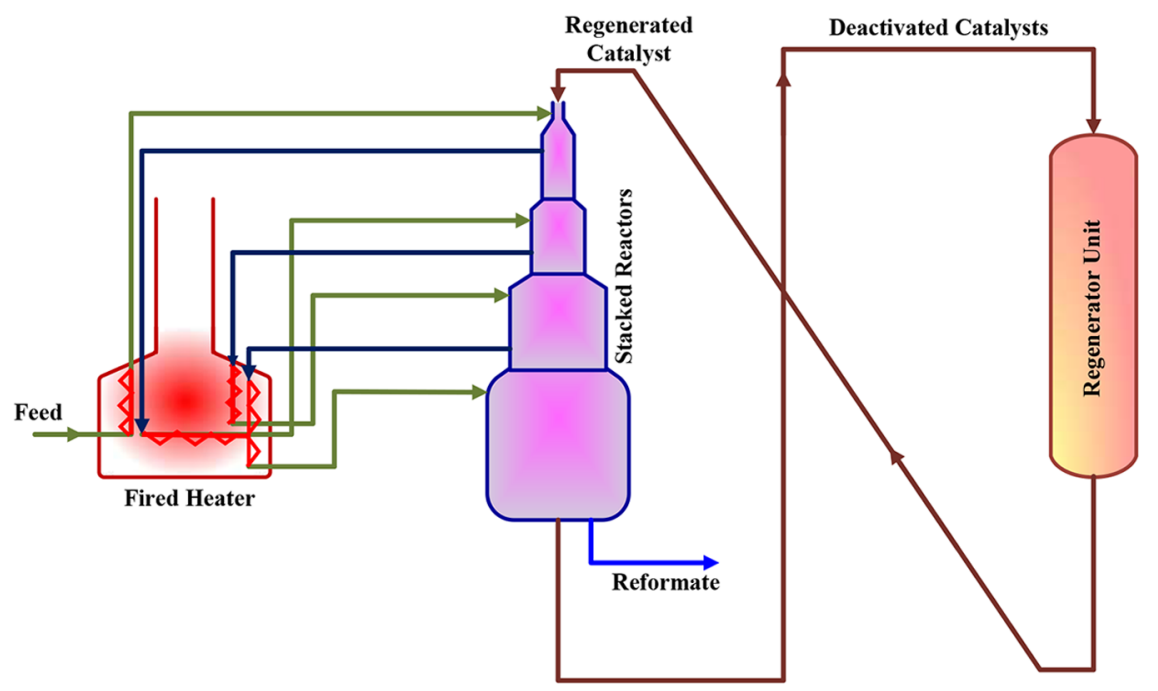

Figure 9. UOP stacked reactor for the naphtha reforming process.

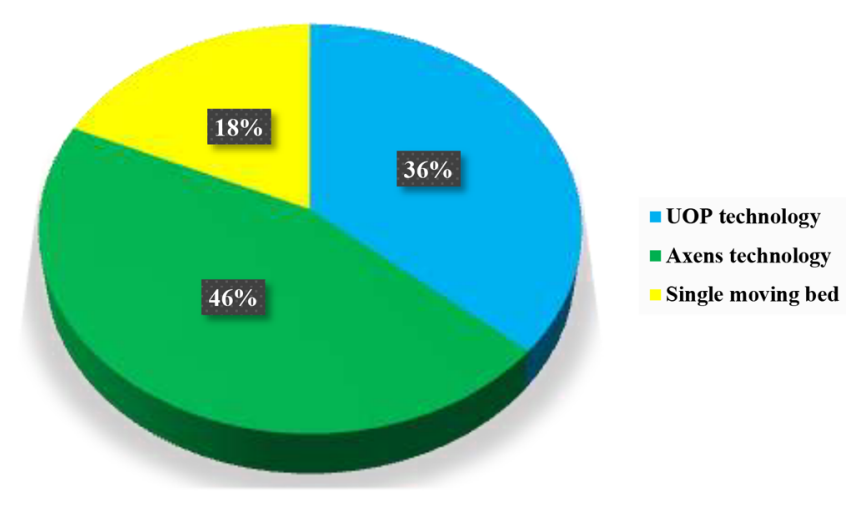

Figure 10. Reactor technology as studied by various researchers.

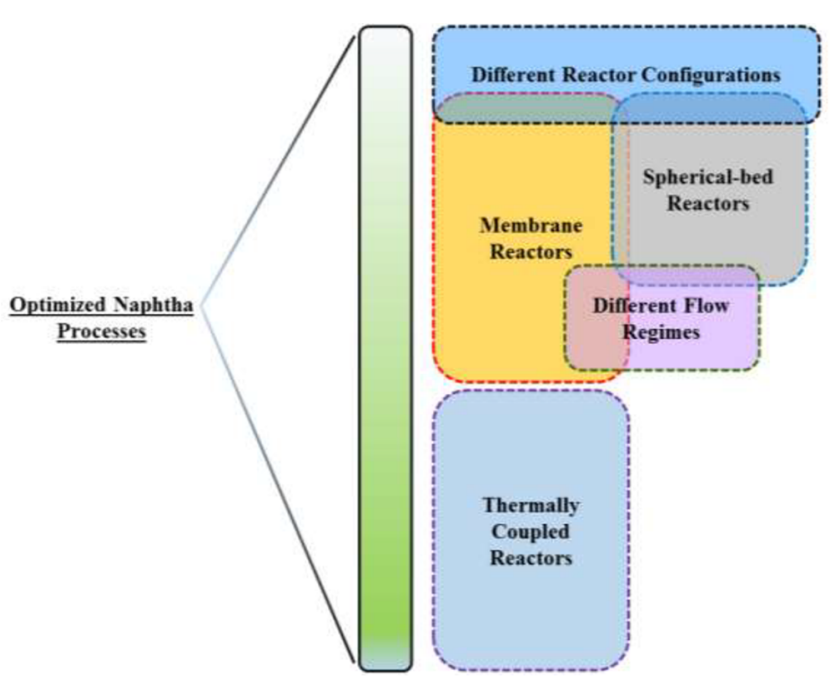

Figure 11. Different methods to improve the performance of the naphtha reforming process.

many reactions take place such as dehydrogenation, ${ }^{203}$ dehydroisomerization, ${ }^{203}$ aromatization, ${ }^{204}$ isomerization, ${ }^{203}$ dehydrocyclization, 203,205 hydroisomerization, 203,205 hydrocracking, $^{203,206}$ and dealkylation. ${ }^{204}$ These reactions, which
Table 4. Exothermic Reactions in Different Studies

\begin{tabular}{|c|c|c|}
\hline entry & exothermic reaction & ref \\
\hline 1 & $\begin{array}{l}\text { hydrogenation of nitrobenzene to } \\
\text { aniline }\end{array}$ & in 2013, Iranshahi et al. ${ }^{251}$ \\
\hline 2 & $\begin{array}{l}\text { hydrogenation of nitrobenzene to } \\
\text { aniline }\end{array}$ & in 2013, Jafari et al. ${ }^{252}$ \\
\hline 3 & oxidation of sulfur dioxide & in 2014 , Karimi et al. ${ }^{253}$ \\
\hline 4 & hydrodealkylation of toluene & in 2017 , Iranshahi et al. ${ }^{254}$ \\
\hline 5 & $\begin{array}{l}\text { hydrogenation of nitrobenzene to } \\
\text { aniline }\end{array}$ & in 2016 , Karimi et al. ${ }^{245}$ \\
\hline 6 & oxidation of sulfur dioxide to $\mathrm{SO}_{3}$ & in 2017 , Saeedi and Iranshahi ${ }^{255}$ \\
\hline 7 & oxidation of sulfur dioxide to $\mathrm{SO}_{3}$ & in 2018 , Iranshahi et al. ${ }^{256}$ \\
\hline
\end{tabular}

occur simultaneously in the reaction bed, are influenced by different parameters.

Naphtha reforming, based on the regeneration cycles, is classified in three main processes ${ }^{207}$ including semiregenerative, $^{208,209}$ cyclic, $^{210,211}$ and continuous regeneration. ${ }^{212,213}$ From the 1970s, when the catalytic continuous regeneration (CCR) process by MBR technology was introduced to the industry, it has attracted worldwide attention, and until now, it has been one of the well-known processes in the petroleum and petrochemical industries. ${ }^{201}$ In the next sections, the conventional and optimized naphtha configurations (thermally coupled reactors and membrane reactors) are reviewed in detail.

3.4.1. Conventional Naphtha Process. 3.4.1.1. Catalyst Deactivation. Many studies have been devoted to investigating the catalyst deactivation of the naphtha process. The catalyst deactivation decreases the catalyst active sites, and it contributes to the reduction of the catalyst performance and, obviously, the production rate. The catalyst deactivation occurs due to several factors such as poisoning, ${ }^{214}$ sintering, ${ }^{214}$ feed impurities, unfavorable byproducts, ${ }^{214}$ and coke deposition. It is worth mentioning that there are two kinds of deactivation procedures including reversible and irreversible. The reversible deactivation occurs due to the leaching of some catalysts' active components from the catalyst structure ${ }^{215}$ or $\mathrm{H}_{2} \mathrm{~S}$ deposition on the catalyst surface. ${ }^{216}$ In these cases, the deactivated catalysts can be regenerated by injection of some special additives to the reaction media. On the other hand, metal functions including arsenic, lead, etc. have a permanent deactivation impact on the catalyst performance. ${ }^{216}$ For the irreversible deactivation, the catalysts 


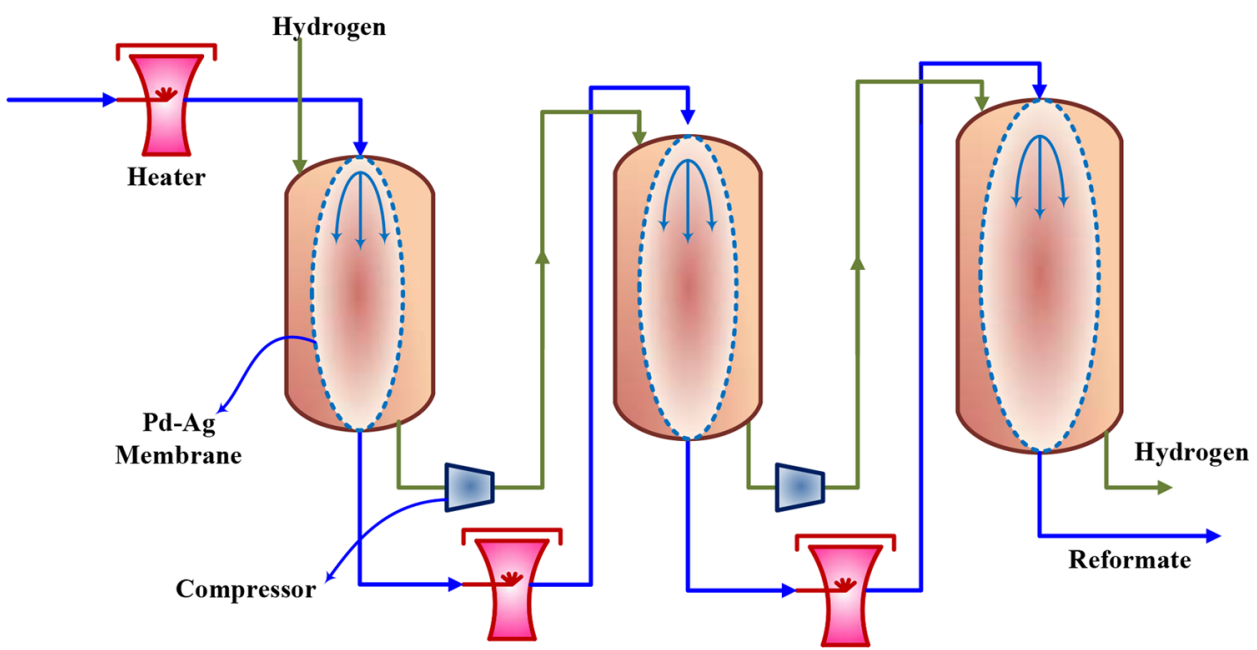

Figure 12. Simple schematic of the membrane catalytic naphtha process.

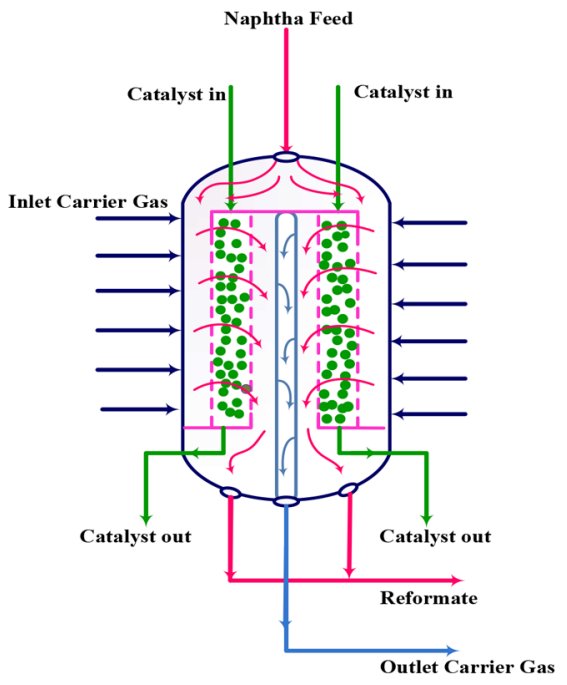

(a)

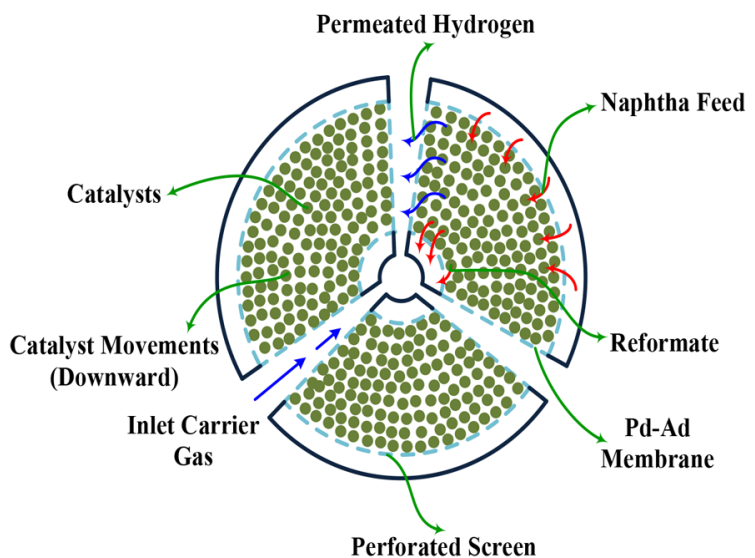

(b)

Figure 13. Simplified schematic of a (a) radial and (b) top view of a membrane reactor of CCR naphtha reforming.

usually should be regenerated in a separated unit or withdrawn and replaced with fresh catalysts. ${ }^{215} \mathrm{Sie}^{215}$ studied the relation of the catalyst deactivation rate and process parameters such as the reactor configuration and the reactor type. He reported that the catalyst performance and the deactivation rate are significantly influenced by the process parameters.

Baghalha et al. studied the impact of the coke deposition on the commercial $\mathrm{Pt}-\mathrm{Re} / \gamma-\mathrm{Al}_{2} \mathrm{O}_{3}$ catalyst of the MBR naphtha process. ${ }^{217}$ They observed that the coke deposited on the micropores and mesopores of the fresh and reused catalysts at a constant layer thickness $(1 \mathrm{~nm})$. Furthermore, they reported the coke deposition rate as the slowest step and the controlling one in comparison with the high rate of the coke ingredient diffusion into the pores. The coke formation and its effects on the catalyst performance at three levels of the active site, the particle, and the reactor were modeled by Froment. ${ }^{214} \mathrm{He}$ concluded that the experimental deactivation models are not robust enough to present the most efficient way to choose the best reactor type; thus, the economic aspects of the catalyst deactivation should be considered in the modeling of the catalyst deactivation phenomena. In another study, ${ }^{218}$ Froment proposed the injection of $\mathrm{H}_{2}$ to the catalytic reforming of the naphtha reactors to obviate the rapid deactivation of the $\mathrm{Pt}-\mathrm{Re}$ /alumina. The impact of the chlorine content on the activity of $\mathrm{Pt}-\mathrm{Re} /$ $\mathrm{Al}_{2} \mathrm{O}_{3}$ in MBRs was investigated by Verderone et al. ${ }^{219}$ They reported a reduction in the catalyst activity by increasing the chlorine content in the feed.

Temperature and $\mathrm{H}_{2}$ partial pressure are the other factors, which have significant effects on the catalyst deactivation. The optimum inlet temperature for the maximum performance of the catalyst was identified by Taskar and Riggs. ${ }^{208}$ The lower temperature profile in the reactors usually contributes to a lower rate of the catalyst deactivation. ${ }^{220}$ There are many deactivation models for the naphtha process such as Levenspiel's deactivation kinetic model (LDKM), ${ }^{221}$ deactivation models with residual activity (DMRA), ${ }^{22}$ etc. Monzon et al. ${ }^{221}$ proposed a mathematical relation between the LDKM factors and the DMRA parameters. They reported an equation, which models the $\mathrm{Pt} / \mathrm{Al}_{2} \mathrm{O}_{3}$ reforming catalyst deactivation, by fouling through the methyl cyclohexane dehydrogenation. In some cases, ${ }^{223,224}$ the weighted average inlet temperature (WAIT) was described as the most important parameter to compensate the catalyst 
deactivation, because of the positive impact of the WAIT on the aromatic yield. $^{224}$

3.4.1.2. Kinetics. Many reactions are involved in the naphtha reforming process through the moving bed reactors, which make the kinetics of this process so complicated. ${ }^{225}$ The first reaction kinetics were reported in 1959 by Smith ${ }^{226}$ and Krane et al., ${ }^{227}$ in which all reactions were considered in the lumped groups. After that, a lot of research improved the naphtha kinetics, in which some pseudocomponents were considered in the network kinetic models. ${ }^{228-232}$ In such a context, the main reactions, corresponding feeds, and products, which were considered in these studies, are summarized in Table S2 (Supporting Information).

As previously mentioned, the reaction kinetics of the catalytic reforming are so intricate; thus, all naphtha reactions are typically categorized in three main classes including paraffins, naphthenes, and aromatics reactions, and it is assumed in each category that the same reactions with similar properties take place. ${ }^{233}$ Sotelo-Boyas and Froment proposed a kinetic model for the naphtha process on the $\mathrm{Pt}-\mathrm{Sn} / \mathrm{Al}_{2} \mathrm{O}_{3}$ catalyst. ${ }^{234}$ The model had an acceptable agreement with experimental values, but on the other hand, it contained a multitude of parameters. The pseudo-homogeneous and heterogeneous reactors were modeled in a radial flow regime, and the predicted yields were in an excellent agreement with the experimental data. ${ }^{234}$

3.4.1.3. Process Modeling and Optimization. Modeling and simulation of the catalytic naphtha reforming is a valuable task to evaluate the differential temperature through the reactors, ${ }^{208}$ products yield, ${ }^{235} \mathrm{RON}^{235}$ reformate percentage, ${ }^{235}$ feed heater duty, ${ }^{208}$ process optimization, ${ }^{208}$ as well as the catalyst activity and lifetime. ${ }^{208}$ Formerly, the naphtha process was considered in the fixed-bed reactors for process modeling and simulation, ${ }^{236}$ but in recent years, on the basis of the requirements of the continuous catalyst regeneration, many researchers have focused on the MBRs modeling, according to the UOP and Axens licenses. $^{237}$ In this way, the reactor configurations, ${ }^{238,239}$ reaction kinetics, ${ }^{233}$ and catalyst deactivation models ${ }^{165}$ were considered to determine the process parameters. The main studies in this area have been summarized in Table S3 (Supporting Information). Also, the distribution of the reactor configurations is depicted in Figure 10.

3.4.1.4. Operational Conditions Effects. There are different parameters which affect the naphtha reforming process such as the pressure, temperature, feed composition, hydrogen/hydrocarbon ratio, and the space velocity. ${ }^{240-242}$ The quality of the naphtha reforming process is evaluated by investigating the variations in the reformate yield, the coke deposition, the octane number, etc. ${ }^{240}$ Also, the $\mathrm{H}_{2} / \mathrm{HC}$ ratio has a direct impact on the coke deposition on the catalysts' surfaces and, consequently, the catalyst lifetime; hence, the $\mathrm{H}_{2} / \mathrm{HC}$ ratio affects the aromatics production yield, indirectly. ${ }^{228}$ On the other hand, many studies have considered the effect of the feed inlet temperature on the product yield. ${ }^{233,243}$

Hongjun et al. ${ }^{244}$ studied the naphtha reforming process in the moving bed reactors in the series. They considered two different operational conditions for the feed composition, feedstock flow rate, and $\mathrm{H}_{2} / \mathrm{HC}$ ratio. They reported that the higher inlet temperature of reactors leads to the higher rate of the coke deposition and the enhancement of the aromatic yield with increasing the space time. Karimi et al. ${ }^{245}$ studied the naphtha reforming process through the MBRs, considering the temperature and $\mathrm{H}_{2} / \mathrm{HC}$ ratio as the most effective parameters on the process. The reaction temperature was also introduced as one of the most important parameters affecting the yield of the reforming process. The catalytic naphtha reforming is a highly endothermic process; hence, the process efficiency decreases as the feed goes through the reactors. They considered the hydrogen as a product through the dehydrogenation of naphthenes and the dehydrocyclization of the paraffins, as a reactant in the hydrocracking reactions of the paraffins and naphthenes, and in the hydrodealkylation of the aromatics. According to the fact that the $\mathrm{H}_{2} / \mathrm{HC}$ ratio has a significant impact on the coke deposition on the catalysts, it should be at an acceptable level to maintain the catalysts lifetime as high as possible. ${ }^{245}$ Also, in another study, $\mathrm{Hu}$ et al. ${ }^{223}$ introduced the WAIT (weighted average inlet temperature), $\mathrm{H}_{2} / \mathrm{HC}$, and the reaction pressure as key parameters on the performance of the naphtha reforming process.

3.4.2. Optimized Naphtha Configurations. Researchers, continuously, have been looking for innovative ways to improve the efficiency of the reforming process. In this way, enhancing the reformate octane number using thermally coupled reactors, ${ }^{246,247}$ membrane reactors, ${ }^{225}$ spherical reactors, ${ }^{248}$ different reactor configurations, ${ }^{225}$ and diverse flow regimes has been investigated, so far. These theoretical methods have been applied together sometimes, which is shown in Figure 11. The designed figure shows the share of each method schematically, by the size of each box.

The refining process is an industry with a high level of energy consumption. ${ }^{249}$ Thus, energy optimization has become an important issue, which directly affects the refinery economics. ${ }^{250}$ Babaqi et al. ${ }^{250}$ studied the heat integration retrofit of the CCR process. They developed a method by pinch analysis technique to save the maximum possible energy. They reduced the utility loads by around $32 \%$, which equals a $4.5 \%$ reduction in the total cost index.

3.4.2.1. Thermally Coupled Reactors. The recuperative coupled reactor is one of the other pioneer strategies to reduce the operational and capital cost of power plants which has attracted much consideration in recent years. ${ }^{246}$ In this way, the reactors are designed and constructed in a way that an exothermic reaction supplies the required energy for the naphtha process. ${ }^{251}$ For example, the huge released energy through the hydrogenation process can be considered as a heat source of endothermic reactions. ${ }^{251}$ The main reactions, which have been studied as a source of energy in the naphtha process, are reported in Table 4 . It can be found that around $61.5 \%$ of the total studies, which were performed in this area, have been devoted to the hydrogenation of the nitrobenzene to aniline, $23.1 \%$ to the oxidation of the sulfur dioxide to $\mathrm{SO}_{3}$, and $15.4 \%$ to the hydrodealkylation of the toluene. Furthermore, studies are ongoing to find new exothermic processes which are more applicable and efficient for the naphtha process.

3.4.2.2. Membrane Reactors. Khosravanipour Mostafazadeh and Rahimpour ${ }^{20}$ first introduced the concept of membrane reactors for catalytic naphtha reforming in 2008. Figure 12 represents a simple schematic of the membrane catalytic naphtha reforming process. In this way, the hydrogen from the shell side penetrates through the membrane to the tube side, where the reactants flow in the reaction beds. Thermodynamically, the reforming reaction is shifted toward the production side, which increases the production rate. ${ }^{220}$

They reported that a $\mathrm{Pd}-\mathrm{Ag}$ membrane can enhance the aromatic production rate in the catalytic reforming process. It is worth mentioning that their proposed model was accomplished in the fixed-bed reactors. Recently, Iranshahi et al. proposed the 


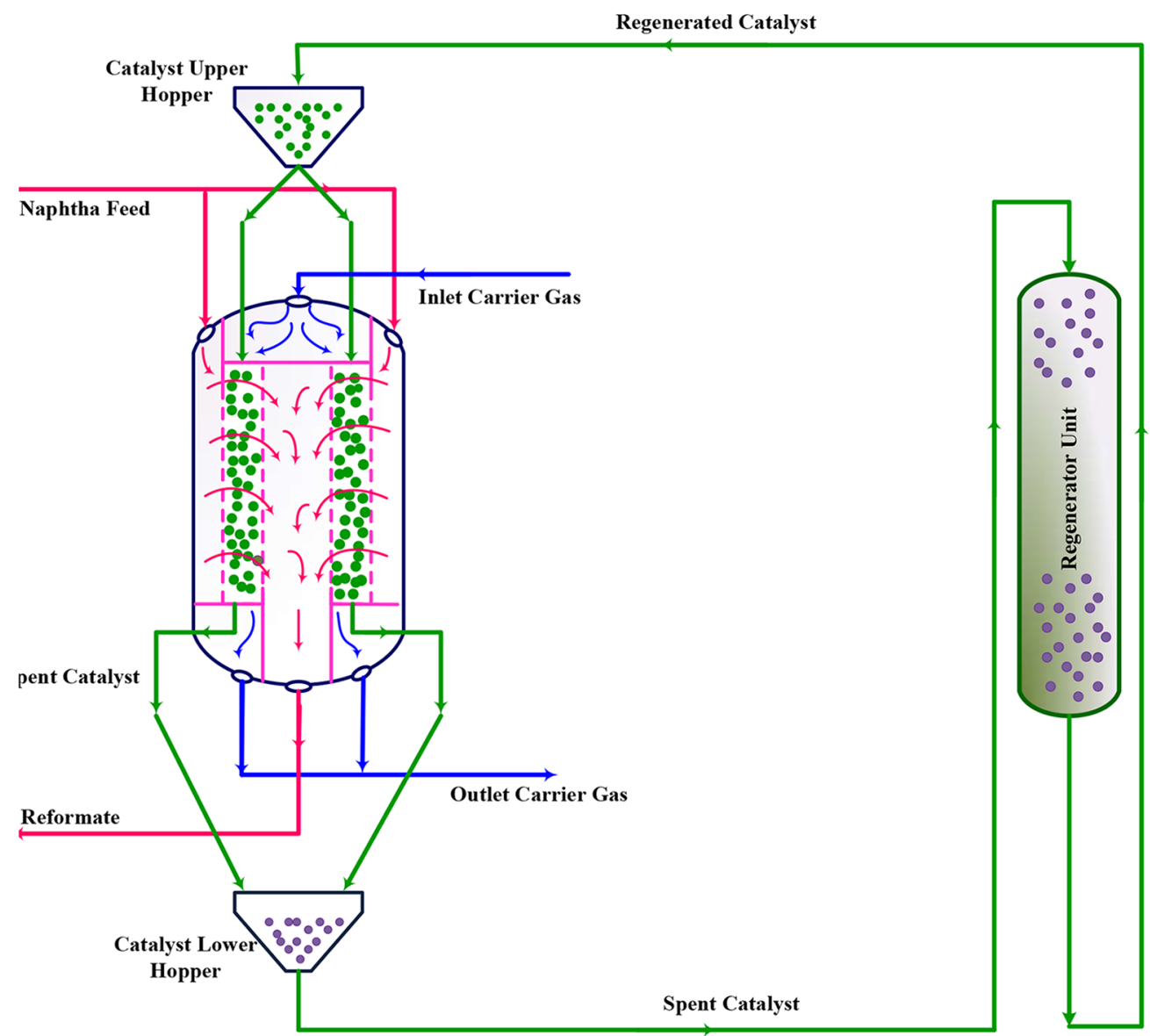

(a)

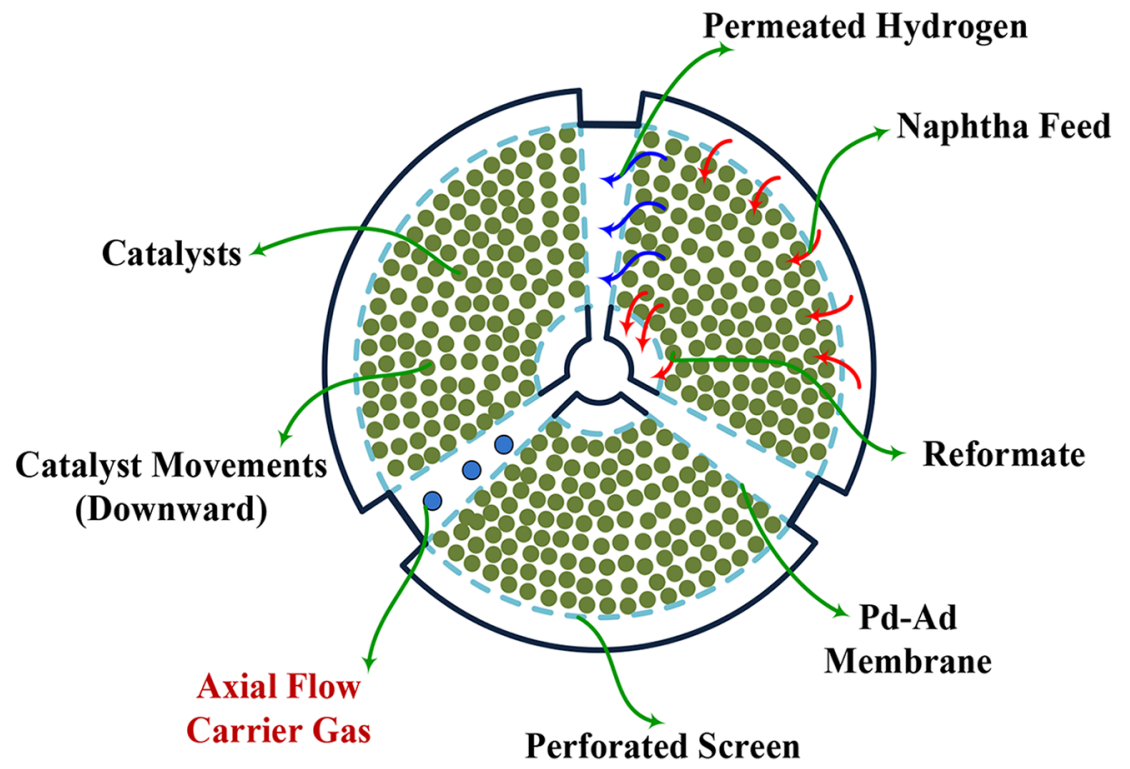

(b)

Figure 14. Radial flow regime for reacting materials and axial flow regime for carrier gas in catalytic naphtha reforming: (a) front view and (b) top view.

naphtha process in MBRs by considering a two-dimensional model (in the radial and axial directions). ${ }^{257}$ They modified the parameters of membrane reactors with the CCR concept, in which the advantages of MBT were applied. Figure 13 shows a membrane reactor for CCR naphtha reforming with a radial flow pattern in the front and top views, schematically. Saeedi and 


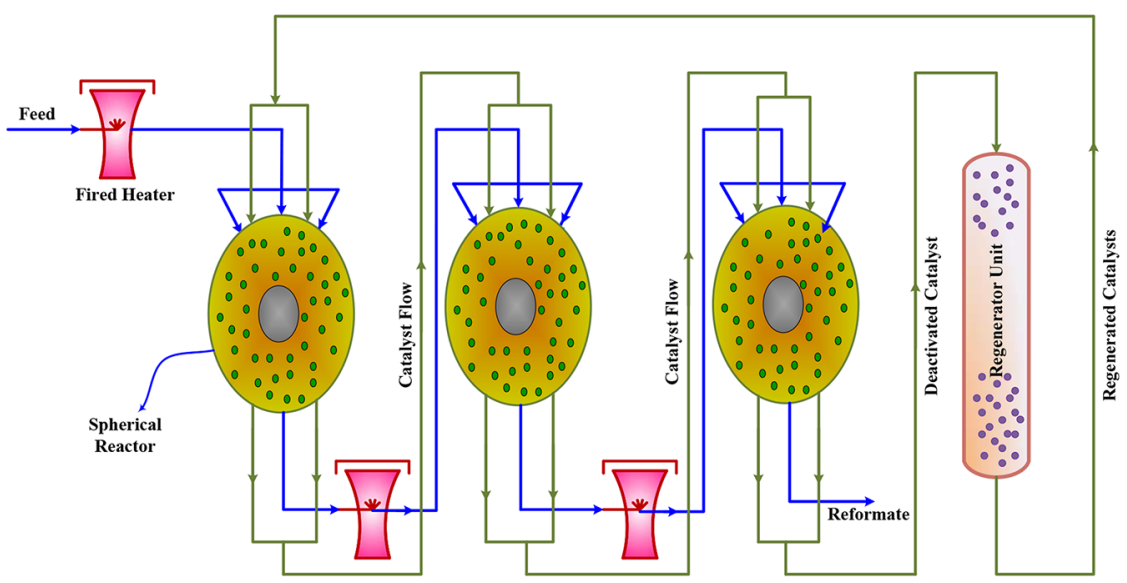

$\mathbf{a}$

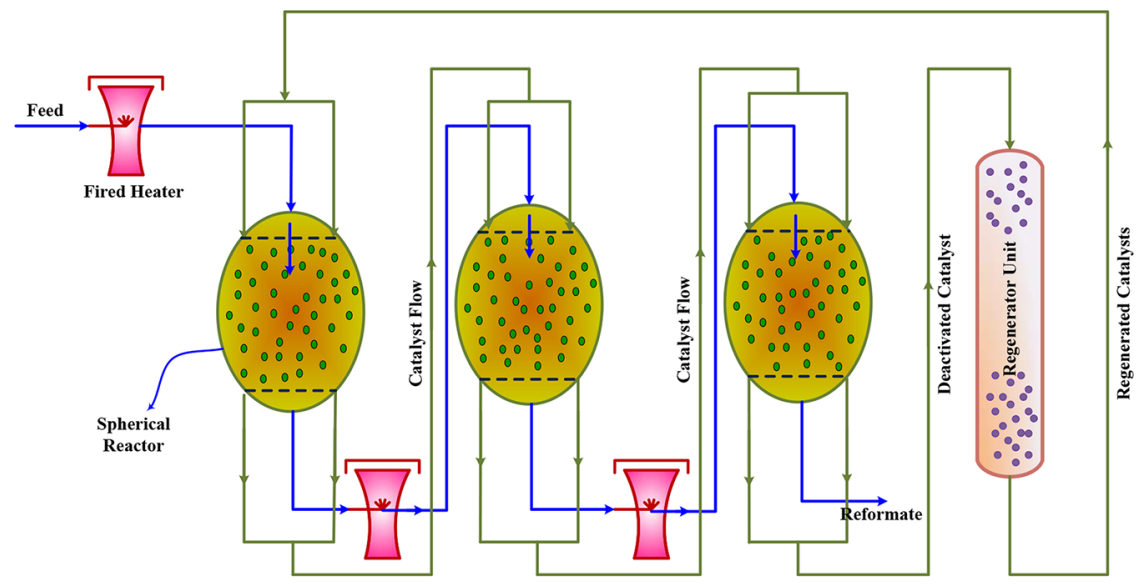

b

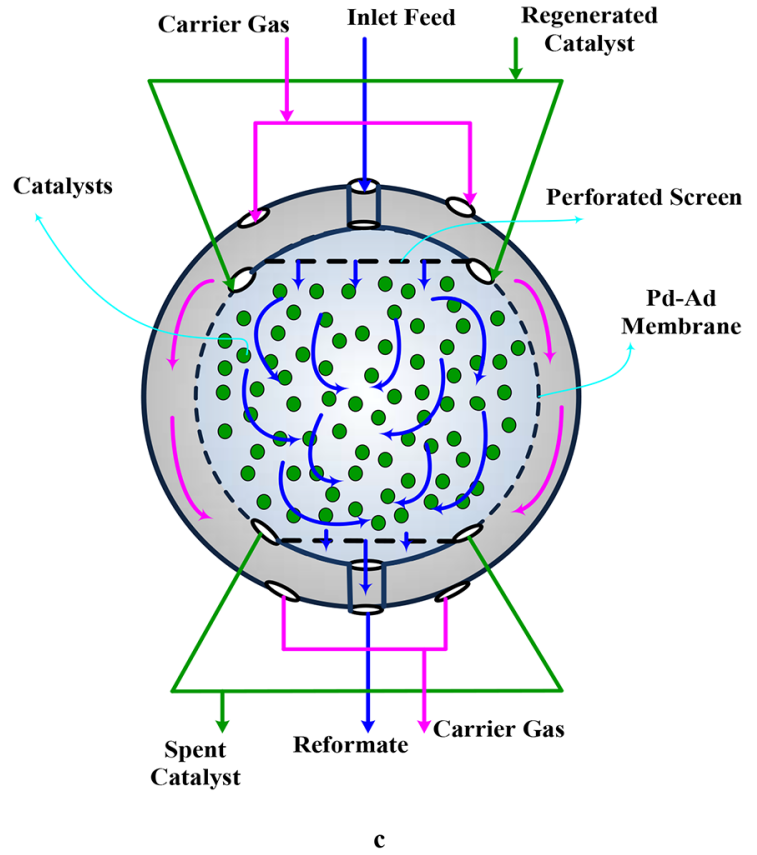

Figure 15. Simple schematic of three spherical MBRs with (a) radial and (b) axial patterns and also with (c) the membrane concept.

Iranshahi performed another study and compared their results with industrial plant data in $2016 .^{258}$ They reported a good agreement between the model outputs and industrial values. They also observed that employing the membrane concept on 
the MBRs enhances the octane number of the gasoline and hydrogen production rate, significantly.

\section{DISCUSSION AND SUGGESTIONS}

The waste management, environmental challenges, and limitations of fossils fuels have been introduced as main concerns of mankind in recent years. ${ }^{259-261}$ On the other hand, the increasing rate of the worldwide energy consumption has intensified the situation and forced researchers to find new sources of energy and improve the quality of available ones. In this way, the MBRs by their widespread applications in chemical looping combustion, pyrolysis technology, fluid catalytic cracking, and the naphtha process have a key role in these industries. The MBR is a valuable technology which can also be coupled with other new processes to develop a highly efficient strategy. $^{225}$

Until around 1960, a high rate of the catalyst deactivation was one of the major restrictions of catalytic reforming, while the advent of MBRs has had a significant effect on this process by developing high-octane reformate and high-quality hydrogen. ${ }^{262}$ Then, the development was pursed by a combination of membrane reactors and conventional ones to enhance the process performance. In this way, the radial and axial flow regimes for reactive compounds and the axial flow regime for the carrier gas were proposed to overcome the high pressure drop in the catalytic packed-bed reactors. ${ }^{248,263}$ For future studies, the packed-bed reactors can be replaced by the MBRs, which is illustrated in Figure 14.

In addition, the idea of employing spherical MBRs instead of conventional ones (tubular MBRs), on the basis of their lower pressure drop through the catalytic bed, can be an excellent strategy in this area for future studies. A schematic diagram of this proposed model for three MBRs in the catalytic reforming process is presented in Figure 15a. On the other hand, the effects of different flow patterns (axial and radial, Figure 15a,b) on the production rate, hydrogen purity, and RON can be investigated as theoretical or experimental studies. Also, upon consideration, the membrane concepts on the spherical MBRs can improve the process performance, ${ }^{263}$ notably (Figure $15 \mathrm{c}$ ).

A combination of spherical MBRs with membrane tubular reactors to develop an efficient configuration for producing highoctane reformate through the CCR process is also an attractive strategy, which can be studied in detail in future works.

Finally, by considering the significance of the process integration (PI) strategy, ${ }^{247}$ merging thermally coupled reactors with proposed spherical/membrane and spherical/radial flow MBRs can be alluring ideas for MBT.

These suggestions show that the innovation in the reactor design and novel configurations can improve the performance of the conventional MBRs, which can be considered for future studies.

\section{CONCLUSIONS}

The moving bed technology was first introduced as a steadystate operation, in the drying process, and then for the catalyst regeneration in the chemical reactions. Today, on the basis of the high efficiency of MBRs, this technology has been widely employed in different industries. In this study, the gathering and discussion all main studies about MBT from the advent of this technology until now were attempted. Through this review, all studies in MBT were categorized in two main classes: experimental and theoretical studies. In this way, the gas- solid moving bed technology as an important and practical application of MBT was indicated. Also, the importance of MBT in the chemical looping combustion, the pyrolysis industry, and the fluid catalytic cracking process, as three of the leading technologies, was discussed in details. In addition, the naphtha reforming process was investigated in two categories: conventional naphtha processes and optimized processes. While the MBT in the catalytic reforming process has been extensively studied in the literature, and it has contributed to some confusing issues, in this work, the classification and merging of the main studies were attempted to aid researchers to have a better grasp about these concepts.

\section{ASSOCIATED CONTENT}

\section{S Supporting Information}

The Supporting Information is available free of charge on the ACS Publications website at DOI: 10.1021/acs.iecr.9b01136.

Different types of reactions in the lumped formulation of naphtha catalytic reforming kinetic models; and reactor type, catalyst nature, and kinetics in different catalytic naphtha reforming processes $(\mathrm{PDF})$

\section{AUTHOR INFORMATION}

\section{Corresponding Authors}

*E-mail: mohsen.karimi@fe.up.pt. Tel.: +351 225081671.

*E-mail: arodrig@fe.up.pt. Tel.: +351225081674.

ORCID

Mohsen Karimi: 0000-0002-1886-5454

Alírio E. Rodrigues: 0000-0002-0715-4761

Notes

The authors declare no competing financial interest.

\section{ACKNOWLEDGMENTS}

This work was financially supported by Project POCI-01-0145FEDER-006984-Associate Laboratory LSRE-LCM funded by FEDER through COMPETE2020-Programa Operacional Competitividade e Internacionalização (POCI), and by national funds through FCT-Fundação para a Ciência e a Tecnologia. M.K. also acknowledges the research grant awarded under Project SFRH/BD/140550/2018 by Portugal Foundation of Science and Technology (FCT).

\section{NOMENCLATURE}

MBR = moving bed reactor

MBT $=$ moving bed technology

$\mathrm{CCR}=$ continuous catalyst regeneration

$\mathrm{SMBR}=$ simulated moving bed reactor

CCS $=$ carbon capture and storage

$\mathrm{CL}=$ chemical looping

$\mathrm{CFD}=$ computational fluid dynamics

LDKM = Levenspiel's deactivation kinetic model

WAIT $=$ weighted average inlet temperature

\section{REFERENCES}

(1) Coker, A. K. Modeling of chemical kinetics and reactor design; Gulf Professional Publishing: Boston, 2001.

(2) Fraga, E. S. Process analysis-the importance of mass and energy balances. In Concepts of Chemical Engineering for Chemists; Simons, S., Ed.; Royal Society of Chemistry: Cambridge, 2015; pp 1-21.

(3) Schaefer, R. J.; Vortmeyer, D.; Watson, C. C. Steady state behavior of moving bed reactors. Chem. Eng. Sci. 1974, 29 (1), 119-127. 
(4) Wei, J.; Cwiklinski, R.; Tomuro, J.; Xiao, J. Temperature differences between phases in a moving bed reactor. Chem. Eng. Sci. 1987, 42 (5), 1175-1185.

(5) Negri, E. D.; Alfano, O. M.; Chiovetta, M. G. Moving-bed reactor model for the direct reduction of hematite. Parametric study. Ind. Eng. Chem. Res. 1995, 34 (12), 4266-4276.

(6) Negri, E. D.; Alfano, O. M.; Chiovetta, M. G. Direct reduction of hematite in a moving-bed reactor. Analysis of the water gas shift reaction effects on the reactor behavior. Ind. Eng. Chem. Res. 1991, 30 (3), 474-482.

(7) Doyle III, F. J.; Jackson, R.; Ginestra, J. C. The phenomenon of pinning in an annular moving bed reactor with crossflow of gas. Chem. Eng. Sci. 1986, 41 (6), 1485-1495.

(8) Arce, P. E.; Alfano, O. M.; Trigatti, I. M.; Cassano, A. E. Heterogeneous model of a moving-bed reactor. 2. Parametric analysis of the steady-state structure. Ind. Eng. Chem. Res. 1989, 28 (2), 165173.

(9) Belghit, A.; Daguenet, M. Study of heat and mass transfer in a chemical moving bed reactor for gasification of carbon using an external radiative source. Int. J. Heat Mass Transfer 1989, 32 (11), 2015-2025.

(10) Enick, R.; Gale, T.; Klara, J.; Jones, J. A mathematical model of an isothermal, flue gas desulforization, copper oxide moving bed reactor. Environ. Prog. 1999, 18 (1), 60-68.

(11) Ye, Y.; Choi, K. Y. Dynamic modeling of a moving-packed-bed reactor for the solid-state polymerization of bisphenol-A polycarbonate. Ind. Eng. Chem. Res. 2008, 47 (10), 3687-3699.

(12) Valipour, M. S.; Saboohi, Y. Modeling of multiple noncatalytic gas-solid reactions in a moving bed of porous pellets based on finite volume method. Heat Mass Transfer 2007, 43 (9), 881-894.

(13) Andrews, W. G. Apparatus for the purification of gas. U.S. Patent 426,092, 1890.

(14) Pivem, A. C.; de Lemos, M. J. Laminar heat transfer in a moving porous bed reactor simulated with a macroscopic two-energy equation model. Int. J. Heat Mass Transfer 2012, 55 (7-8), 1922-1930.

(15) de Lemos, M. J.; Pivem, A. C. Turbulent heat transfer in a counterflow moving porous bed using a two-energy equation model. Int. J. Heat Mass Transfer 2014, 72, 98-113.

(16) Ku, Y.; Wu, H.-C.; Chiu, P.-C.; Tseng, Y.-H.; Kuo, Y.-L. Methane combustion by moving bed fuel reactor with $\mathrm{Fe} 2 \mathrm{O} 3 / \mathrm{Al} 2 \mathrm{O} 3$ oxygen carriers. Appl. Energy 2014, 113, 1909-1915.

(17) Sahariah, B. P.; Anandkumar, J.; Chakraborty, S. Stability of continuous and fed batch sequential anaerobic-anoxic-aerobic moving bed bioreactor systems at phenol shock load application. Environ. Technol. 2018, 39 (15), 1898-1907.

(18) Bassin, J. P.; Dezotti, M. Moving bed biofilm reactor (MBBR). In Advanced Biological Processes for Wastewater Treatment; Springer, 2018; pp 37-74.

(19) Brosseau, C.; Émile, B.; Labelle, M.-A.; Laflamme, É.; Dold, P. L.; Comeau, Y. Compact secondary treatment train combining a lab-scale moving bed biofilm reactor and enhanced flotation processes. Water Res. 2016, 106, 571-582.

(20) Leyva-Díaz, J. C.; Martín-Pascual, J.; Poyatos, J. M. Moving bed biofilm reactor to treat wastewater. Int. J. Environ. Sci. Technol. 2017, 14 (4), 881-910.

(21) Schneiderbauer, S.; Aigner, A.; Pirker, S. A comprehensive frictional-kinetic model for gas-particle flows: Analysis of fluidized and moving bed regimes. Chem. Eng. Sci. 2012, 80, 279-292.

(22) Niksiar, A.; Rahimi, A. Design of a moving bed reactor for the production of uranium tetrafluoride based on mathematical modeling. Chem. Eng. Sci. 2010, 65 (10), 3147-3157.

(23) Maddah, H. A. A Comparative Study between Propane Dehydrogenation (PDH) Technologies and Plants in Saudi Arabia. Am. Sci. Res. J. Eng., Technol., Sci. 2018, 45 (1), 49-63.

(24) Dudukovic, M. P. Trends in catalytic reaction engineering. Catal. Today 1999, 48 (1-4), 5-15.

(25) The-Crankshaft Publishing's Home Page. http://what-whenhow.com (accessed August 2018).
(26) Yuan, Z.; Chen, B. Process synthesis for addressing the sustainable energy systems and environmental issues. AIChE J. 2012, 58 (11), 3370-3389.

(27) Dou, B.; Zhang, H.; Cui, G.; Wang, Z.; Jiang, B.; Wang, K.; Chen, $\mathrm{H}$.; $\mathrm{Xu}, \mathrm{Y}$. Hydrogen production and reduction of Ni-based oxygen carriers during chemical looping steam reforming of ethanol in a fixedbed reactor. Int. J. Hydrogen Energy 2017, 42 (42), 26217-26230.

(28) Dou, B.; Zhang, H.; Cui, G.; Wang, Z.; Jiang, B.; Wang, K.; Chen, $\mathrm{H}$.; $\mathrm{Xu}, \mathrm{Y}$. Hydrogen production by sorption-enhanced chemical looping steam reforming of ethanol in an alternating fixed-bed reactor: Sorbent to catalyst ratio dependencies. Energy Convers. Manage. 2018, $155,243-252$.

(29) Toukan, A.; Alexander, V.; AlBazzaz, H.; Al-Dahhan, M. H. Identification of flow regime in a cocurrent gas-Liquid upflow moving packed bed reactor using gamma ray densitometry. Chem. Eng. Sci. 2017, 168, 380-390.

(30) Solé, A.; Martorell, I.; Cabeza, L. F. State of the art on gas-solid thermochemical energy storage systems and reactors for building applications. Renewable Sustainable Energy Rev. 2015, 47, 386-398.

(31) Bassin, J. P.; Dezotti, M.; Sant'Anna, G. L., Jr. Nitrification of industrial and domestic saline wastewaters in moving bed biofilm reactor and sequencing batch reactor. J. Hazard. Mater. 2011, 185 (1), $242-248$.

(32) Rotating Bed Reactor Applications and Products; SpinChem AB: Umea, Sweden; http://www.spinchem.com.

(33) Lee, S. Y.; Nielsen, J.; Stephanopoulos, G. Industrial Biotechnology: Products and Processes; John Wiley \& Sons, 2016.

(34) Argyle, M. D.; Bartholomew, C. H. Heterogeneous catalyst deactivation and regeneration: a review. Catalysts 2015, 5 (1), 145269

(35) Gavrilović, L.; Brandin, J.; Holmen, A.; Venvik, H.J.; Myrstad, R.; Blekkan, E. A. Fischer-Tropsch synthesis-Investigation of the deactivation of a Co catalyst by exposure to aerosol particles of potassium salt. Appl. Catal., B 2018, 230, 203-209.

(36) Paasikallio, V.; Lindfors, C.; Kuoppala, E.; Solantausta, Y.; Oasmaa, A.; Lehto, J.; Lehtonen, J. Product quality and catalyst deactivation in a four day catalytic fast pyrolysis production run. Green Chem. 2014, 16 (7), 3549-3559.

(37) Rodríguez, E.; Félix, G.; Ancheyta, J.; Trejo, F. Modeling of hydrotreating catalyst deactivation for heavy oil hydrocarbons. Fuel 2018, 225, 118-133.

(38) Argyle, M. D.; Frost, T. S.; Bartholomew, C. H. Cobalt fischertropsch catalyst deactivation modeled using generalized power law expressions. Top. Catal. 2014, 57 (6-9), 415-429.

(39) Rytter, E.; Holmen, A. Deactivation and regeneration of commercial type Fischer-Tropsch Co-catalysts-A mini-review. Catalysts 2015, 5 (2), 478-499.

(40) Lange, J. P. Renewable feedstocks: the problem of catalyst deactivation and its mitigation. Angew. Chem., Int. Ed. 2015, 54 (45), 13186-13197.

(41) Satyanarayana, C. V.; Srikant, D.; Gurav, H. R. Catalyst Deactivation and Regeneration. In Industrial Catalytic Processes for Fine and Specialty Chemicals; Joshi, S. S., Ranade, V. V., Eds.; Elsevier: Amsterdam, 2016; pp 187-219.

(42) Braz, C. G.; Mendes, A.; Rocha, J.; Alvim, R.; Matos, H. A. Model of an industrial multitubular reactor for methanol to formaldehyde oxidation in the presence of catalyst deactivation. Chem. Eng. Sci. 2019, 195, 347.

(43) Megías-Sayago, C.; Bobadilla, L. F.; Ivanova, S.; Penkova, A.; Centeno, M. A.; Odriozola, J. A. Gold catalyst recycling study in basefree glucose oxidation reaction. Catal. Today 2018, 301, 72-77.

(44) Emerson Process Management Documentation Home Page. http://www.documentation.emersonprocess.com (accessed August 2018).

(45) Honeywell International Inc. Home Page. https://www.uop.com (accessed September 2018).

(46) Jayaraman, V. K.; Kulkarni, B. D. Catalytic Reactors: A Review. In Chemical Engineering and Chemical Process Technology-Vol. III: Chemical Reaction Engineering; Pohorecki, R., Bridgwater, J., Molzahn, M., Gani, 
R., Gallegos, C., Eds.; Eolss Publishers: United Kingdom, 2010; pp $122-142$.

(47) Santos, B.; Pereira, C.; Silva, V.; Loureiro, J.; Rodrigues, A. Design of a true moving bed reactor for the direct synthesis of dimethyl carbonate. Chem. Eng. Sci. 2015, 123, 406-419.

(48) Kondrashov, D. O. The role of interstage separation of reformate in improving the efficiency of a fixed-bed catalytic reforming process. Pet. Chem. 2016, 56 (9), 863-868.

(49) Regalado, M. J. C.; Belonio, A. T.; Villota, K. C.; Rafael, M. L.; Castillo, P. R. Design, Testing, and Evaluation of a Hydrous Bioethanol Distiller for the Production of Fuel-grade Alcohol from Nipa Sap (Nypa fruticans). Appl. Eng. Agri. 2018, 34 (5), 759-765.

(50) Xiao, Y.; Xu, S.; Song, Y.; Wang, C.; Ouyang, S. Gasification of low-rank coal for hydrogen-rich gas production in a dual loop gasification system. Fuel Process. Technol. 2018, 171, 110-116.

(51) Myllymaa, T.; Holmberg, H.; Ahtila, P. Techno-economic evaluation of biomass drying in moving beds: The effect of drying kinetics on drying costs. Drying Technol. 2018, 1-14.

(52) Giordano, C.; Spennati, F.; Mori, G.; Munz, G.; Vannini, C. The microbial community in a moving bed biotrickling filter operated to remove hydrogen sulfide from gas streams. Syst. Appl. Microbiol. 2018, 41 (4), 399-407.

(53) Mannina, G.; Capodici, M.; Cosenza, A.; Di Trapani, D.; Ekama, G. A. The effect of the solids and hydraulic retention time on moving bed membrane bioreactor performance. J. Cleaner Prod. 2018, 170, $1305-1315$.

(54) Mulvaney III, R. C.; Brandner, K. J.; Arakawa, S. T.; Anderson, P. Apparatus for controlling reaction temperatures. U.S. Patent 6,432,369, 2002.

(55) Continuous catalytic reforming-catalyst valves; Application Report 2721/06/01, 5/2011, for Metso Automation Inc.; http:// www.metso.com/valves.

(56) Leyva-Díaz, J.; González-Martínez, A.; González-López, J.; Muñío, M.; Poyatos, J. Kinetic modeling and microbiological study of two-step nitrification in a membrane bioreactor and hybrid moving bed biofilm reactor-membrane bioreactor for wastewater treatment. Chem. Eng. J. 2015, 259, 692-702.

(57) Fatehifar, M.; Borghei, S. M. Application of moving bed biofilm reactor in the removal of pharmaceutical compounds (diclofenac and ibuprofen). J. Environ. Chem. Eng. 2018, 6 (4), 5530-5535.

(58) Bachmann Pinto, H.; Miguel de Souza, B.; Dezotti, M. Treatment of a pesticide industry wastewater mixture in a moving bed biofilm reactor followed by conventional and membrane processes for water reuse. J. Cleaner Prod. 2018, 201, 1061-1070.

(59) Mazioti, A. A.; Stasinakis, A. S.; Pantazi, Y.; Andersen, H. R. Biodegradation of benzotriazoles and hydroxy-benzothiazole in wastewater by activated sludge and moving bed biofilm reactor systems. Bioresour. Technol. 2015, 192, 627-635.

(60) Jiang, Q.; Ngo, H. H.; Nghiem, L. D.; Hai, F. I.; Price, W. E.; Zhang, J.; Liang, S.; Deng, L.; Guo, W. Effect of hydraulic retention time on the performance of a hybrid moving bed biofilm reactor-membrane bioreactor system for micropollutants removal from municipal wastewater. Bioresour. Technol. 2018, 247, 1228-1232.

(61) Chrispim, M. C.; Nolasco, M. A. Greywater treatment using a moving bed biofilm reactor at a university campus in Brazil. J. Cleaner Prod. 2017, 142, 290-296.

(62) Luo, S.; Zhou, Y.; Yi, C. Hydrogen-rich gas production from biomass catalytic gasification using hot blast furnace slag as heat carrier and catalyst in moving-bed reactor. Int. J. Hydrogen Energy 2012, 37 (20), 15081-15085.

(63) Rossier, M.; Schaetz, A.; Athanassiou, E. K.; Grass, R. N.; Stark, W. J. Reversible As (V) adsorption on magnetic nanoparticles and $\mathrm{pH}$ dependent desorption concentrates dilute solutions and realizes true moving bed reactor systems. Chem. Eng. J. 2011, 175, 244-250.

(64) Badillo-Hernandez, U.; Alvarez-Icaza, L.; Alvarez, J. Model design of a class of moving-bed tubular gasification reactors. Chem. Eng. Sci. 2013, 101, 674-685.

(65) Gundlapally, S. R.; Agrawal, R.; West, D. H.; Balakotaiah, V. Influence of non-uniform activity and conductivity on stationary and moving patterns in catalytic reactors. Chem. Eng. Sci. 2010, 65 (5), $1522-1538$.

(66) Wang, X.; Bi, X.; Hem, L. J.; Ratnaweera, H. Microbial community composition of a multi-stage moving bed biofilm reactor and its interaction with kinetic model parameters estimation. J. Environ. Manage. 2018, 218, 340-347.

(67) Wang, X.-J.; Xia, S.-Q.; Chen, L.; Zhao, J.-F.; Renault, N.; Chovelon, J.-M. Nutrients removal from municipal wastewater by chemical precipitation in a moving bed biofilm reactor. Process Biochem. 2006, 41 (4), 824-828.

(68) Chen, S.; Sun, D.; Chung, J.-S. Simultaneous removal of COD and ammonium from landfill leachate using an anaerobic-aerobic moving-bed biofilm reactor system. Waste Manage. 2008, 28 (2), 339346.

(69) Faria, R. P. V.; Graca, N. S.; Rodrigues, A. E. Green fuels and fuel additives; Production in simulated moving bed reactors. In Intensification of Biobased Processes; Gorak, A., Stankiewicz, A., Eds.; Royal Society of Chemistry: United Kingdom, 2018; pp 145-165.

(70) Silva, V. M.; Gandi, G. K.; Rodrigues, A. E. Development of simulated moving bed reactor using a cation exchange resin as a catalyst and adsorbent for the synthesis of acetals. In Ion Exchange and Solvent Extraction; CRC Press, 2007; pp 54-110.

(71) Pereira, C. S.; Rodrigues, A. E. Process intensification: New technologies (SMBR and PermSMBR) for the synthesis of acetals. Catal. Today 2013, 218, 148-152.

(72) Silva, V. M.; Pereira, C. S.; Rodrigues, A. E. PermSMBR-A new hybrid technology: Application on green solvent and biofuel production. AIChE J. 2011, 57 (7), 1840-1851.

(73) Pereira, C. S.; Zabka, M.; Silva, V. M.; Rodrigues, A. E. A novel process for the ethyl lactate synthesis in a simulated moving bed reactor (SMBR). Chem. Eng. Sci. 2009, 64 (14), 3301-3310.

(74) Gyani, V. C.; Reddy, B.; Bhat, R.; Mahajani, S. Simulated moving bed reactor for the synthesis of 2-ethylhexyl acetate. Part I: experiments and simulations. Ind. Eng. Chem. Res. 2014, 53 (41), 15811-15823.

(75) Lee, J. W.; Horváth, Z.; O’Brien, A. G.; Seeberger, P. H.; SeidelMorgenstern, A. Design and optimization of coupling a continuously operated reactor with simulated moving bed chromatography. Chem. Eng. J. 2014, 251, 355-370.

(76) Fan, L.-S.; Zeng, L.; Wang, W.; Luo, S. Chemical looping processes for $\mathrm{CO}_{2}$ capture and carbonaceous fuel conversion-prospect and opportunity. Energy Environ. Sci. 2012, 5 (6), 7254-7280.

(77) Karimi, M.; C. Silva, J. A.; Gonçalves, C. N. D. P.; Diaz de Tuesta, J. L.; Rodrigues, A. E.; Gomes, H. T. $\mathrm{CO}_{2}$ capture in chemically and thermally modified activated carbons using breakthrough measurements: experimental and modeling study. Ind. Eng. Chem. Res. 2018, 57 (32), 11154-11166.

(78) Henrique, A.; Karimi, M.; Silva, J. A. C.; Rodrigues, A. E. Analyses of Adsorption Behavior of $\mathrm{CO}_{2}, \mathrm{CH}_{4}$ and $\mathrm{N}_{2}$ on Different Types of BETA Zeolites. Chem. Eng. Technol. 2019, 42 (2), 327-342.

(79) Moghtaderi, B. Review of the recent chemical looping process developments for novel energy and fuel applications. Energy Fuels 2012, $26(1), 15-40$.

(80) Pramanick, B.; Vazquez-Pinon, M.; Torres-Castro, A.; MartinezChapaa, S. O.; Madou, M. Effect of pyrolysis process parameters on electrical, physical, chemical and electro-chemical properties of SU-8derived carbon structures fabricated using the C-MEMS process. Mater. Today: Proc. 2018, 5 (3), 9669-9682.

(81) Hameed, Z.; Aman, Z.; Naqvi, S. R.; Tariq, R.; Ali, I.; Makki, A. A. Kinetic and thermodynamic analyses of sugar cane bagasse and sewage sludge co-pyrolysis process. Energy Fuels 2018, 32 (9), 9551-9558.

(82) Li, F.; Zeng, L.; Ramkumar, S.; Sridhar, D.; Iyer, M.; Fan, L. S. Chemical looping gasification using gaseous fuels. In Chemical Looping Systems for Fossil Energy Conversions; John Wiley and Sons: New York, 2010; pp 215-300.

(83) Luo, S.; Bayham, S.; Zeng, L.; McGiveron, O.; Chung, E.; Majumder, A.; Fan, L.-S. Conversion of metallurgical coke and coal using a coal direct chemical looping (CDCL) moving bed reactor. Appl. Energy 2014, 118, 300-308. 
(84) Adanez, J.; Abad, A.; Garcia-Labiano, F.; Gayan, P.; Luis, F. Progress in chemical-looping combustion and reforming technologies. Prog. Energy Combust. Sci. 2012, 38 (2), 215-282.

(85) Chiu, P.-C.; Ku, Y.; Wu, H.-C.; Kuo, Y.-L.; Tseng, Y.-H. Chemical looping combustion of polyurethane and polypropylene in an annular dual-tube moving bed reactor with iron-based oxygen carrier. Fuel 2014, 135, 146-152.

(86) Zeng, L.; Tong, A.; Kathe, M.; Bayham, S.; Fan, L.-S. Iron oxide looping for natural gas conversion in a countercurrent moving bed reactor. Appl. Energy 2015, 157, 338-347.

(87) Hong, Y. S.; Kang, K. S.; Park, C. S.; Kim, S. D.; Bae, J. W.; Nam, J. W.; Lee, Y.; Lee, D. H. Solid mass flux in a chemical-looping process for hydrogen production in a multistage circulating moving bed reactor. Int. J. Hydrogen Energy 2013, 38 (14), 6052-6058.

(88) Wu, H.-C.; Ku, Y.; Tsai, H.-H.; Kuo, Y.-L.; Tseng, Y.-H. Rice husk as solid fuel for chemical looping combustion in an annular dualtube moving bed reactor. Chem. Eng. J. 2015, 280, 82-89.

(89) Dou, B.; Song, Y.; Wang, C.; Chen, H.; Yang, M.; Xu, Y. Hydrogen production by enhanced-sorption chemical looping steam reforming of glycerol in moving-bed reactors. Appl. Energy 2014, 130, $342-349$.

(90) Kang, K.-S.; Kim, C.-H.; Bae, K.-K.; Cho, W.-C.; Jeong, S.-U.; Kim, S.-H.; Park, C.-S. Modeling a counter-current moving bed for fuel and steam reactors in the TRCL process. Int. J. Hydrogen Energy 2012, 37 (4), 3251-3260.

(91) Tong, A.; Zeng, L.; Kathe, M. V.; Sridhar, D.; Fan, L.-S. Application of the moving-bed chemical looping process for high methane conversion. Energy Fuels 2013, 27 (8), 4119-4128.

(92) Chiu, P.-C.; Ku, Y.; Wu, H.-C.; Kuo, Y.-L.; Tseng, Y.-H. Spent isopropanol solution as possible liquid fuel for moving bed reactor in chemical looping combustion. Energy Fuels 2014, 28 (1), 657-665.

(93) Lyngfelt, A. Chemical-looping combustion of solid fuels-status of development. Appl. Energy 2014, 113, 1869-1873.

(94) Chen, C.; Lee, H.-H.; Chen, W.; Chang, Y.-C.; Wang, E.; Shen, C.-H.; Huang, K.-E. Study of an iron-based oxygen carrier on the moving bed chemical looping system. Energy Fuels 2018, 32 (3), 36603667.

(95) Moldenhauer, P.; Rydén, M.; Mattisson, T.; Jamal, A.; Lyngfelt, A. Chemical-looping combustion with heavy liquid fuels in a $10 \mathrm{~kW}$ pilot plant. Fuel Process. Technol. 2017, 156, 124-137.

(96) Alalwan, H. A.; Mason, S. E.; Grassian, V. H.; Cwiertny, D. M. $\alpha$ $\mathrm{Fe} 2 \mathrm{O} 3$ nanoparticles as oxygen carriers for chemical looping combustion: An integrated materials characterization approach to understanding oxygen carrier performance, reduction mechanism, and particle size effects. Energy Fuels 2018, 32 (7), 7959-7970.

(97) Ostace, A.; Lee, A.; Okoli, C. O.; Burgard, A. P.; Miller, D. C.; Bhattacharyya, D. Mathematical modeling of a moving-bed reactor for chemical looping combustion of methane. In Comput.-Aided Chem. Eng.; Elsevier: Amsterdam, 2018; Vol. 44, pp 325-330.

(98) Mendiara, T.; Gayán, P.; García-Labiano, F.; de Diego, L.; PérezAstray, A.; Izquierdo, M. T.; Abad, A.; Adánez, J. Chemical looping combustion of biomass: an approach to BECCS. Energy Procedia 2017, 114, 6021-6029.

(99) Kuo, P.-C.; Chen, J.-R.; Wu, W.; Chang, J.-S. Hydrogen production from biomass using iron-based chemical looping technology: Validation, optimization, and efficiency. Chem. Eng. J. 2018, 337, 405-415.

(100) Xu, D.; Zhang, Y.; Hsieh, T.-L.; Guo, M.; Qin, L.; Chung, C.; Fan, L.-S.; Tong, A. A novel chemical looping partial oxidation process for thermochemical conversion of biomass to syngas. Appl. Energy 2018, 222, 119-131.

(101) Stevens, R.; Newby, R.; Keairns, D.; Woods, M. Moving Bed Chemical Looping Combustion (MB-CLC) Reference Plant Design and Sensitivity Studies; National Energy Technology Laboratory (NETL), 2016.

(102) Ku, Y.; Wu, H.-C.; Chang, C.-W.; Shiu, S.-H. Chemical looping with air separation (CLAS) in a moving bed reactor with $\mathrm{CuO} / \mathrm{ZrO}_{2}$ oxygen carriers. Int. J. Greenhouse Gas Control 2018, 70, 225-235.
(103) Yang, M.; Banerjee, S.; Agarwal, R. K. Transient cold flow simulation of fast fluidized bed fuel reactors for chemical looping combustion. J. Energy Resour. Technol. 2018, 140 (11), 112203112209.

(104) Fan, L. S.; Zeng, L.; Luo, S. Chemical looping technology platform. AIChE J. 2015, 61 (1), 2-22.

(105) Kortunov, P.; Vasenkov, S.; Kärger, J.; Fé Elía, M.; Perez, M.; Stöcker, M.; Papadopoulos, G. K.; Theodorou, D.; Drescher, B.; McElhiney, G. Diffusion in fluid catalytic cracking catalysts on various displacement scales and its role in catalytic performance. Chem. Mater. 2005, 17 (9), 2466-2474.

(106) Yang, Q.; Berrouk, A. S.; Du, Y.; Zhao, H.; Yang, C.; Rakib, M. A.; Mohamed, A.; Taher, A. CFD investigation of hydrodynamics, heat transfer and cracking reactions in a large-scale fluidized catalytic cracking riser. Appl. Math. Modell. 2016, 40 (21-22), 9378-9397.

(107) Li, Z.; Wang, G.; Liu, Y.; Wang, H.; Liang, Y.; Xu, C.; Gao, J. Catalytic cracking constraints analysis and divisional fluid catalytic cracking process for coker gas oil. Energy Fuels 2012, 26 (4), 22812291.

(108) Vogt, E.; Weckhuysen, B. Fluid catalytic cracking: recent developments on the grand old lady of zeolite catalysis. Chem. Soc. Rev. 2015, 44 (20), 7342-7370.

(109) Liu, X.; Liu, S.; Liu, Y. A potential substitute for CeY zeolite used in fluid catalytic cracking process. Microporous Mesoporous Mater. 2016, 226, 162-168.

(110) Arandes, J. M.; Abajo, I.; Fernández, I.; Azkoiti, M. J.; Bilbao, J. Effect of HZSM-5 zeolite addition to a fluid catalytic cracking catalyst. Study in a laboratory reactor operating under industrial conditions. Ind. Eng. Chem. Res. 2000, 39 (6), 1917-1924.

(111) Polato, C. M.; Rodrigues, A. C.; Monteiro, J. L.; Henriques, C. A. High surface area $\mathrm{Mn}, \mathrm{Mg}, \mathrm{Al}$-spinels as catalyst additives for $\mathrm{SOx}$ abatement in fluid catalytic cracking units. Ind. Eng. Chem. Res. 2010, 49 (3), 1252-1258.

(112) Knöll, J.; Singh, U.; Nicolich, J.; Gonzalez, R.; Ziebarth, M.; Fougret, C.; Brandt, S. Unit cell volume as a measure of dealumination of ZSM-5 in fluid catalytic cracking catalyst. Ind. Eng. Chem. Res. 2014, 53 (42), 16270-16274.

(113) Bai, P.; Xie, M.; Etim, U. J.; Xing, W.; Wu, P.; Zhang, Y.; Liu, B.; Wang, Y.; Qiao, K.; Yan, Z. Zeolite Y mother liquor modified $\gamma$-Al2O3 with enhanced Brönsted acidity as active matrix to improve the performance of fluid catalytic cracking catalyst. Ind. Eng. Chem. Res. 2018, 57 (5), 1389-1398.

(114) Krumeich, F.; Ihli, J.; Shu, Y.; Cheng, W.-C.; van Bokhoven, J. A. Structural Changes in Deactivated Fluid Catalytic Cracking Catalysts Determined by Electron Microscopy. ACS Catal. 2018, 8 (5), 45914599.

(115) Barth, J.-O.; Jentys, A.; Lercher, J. A. Elementary reactions and intermediate species formed during the oxidative regeneration of spent fluid catalytic cracking catalysts. Ind. Eng. Chem. Res. 2004, 43 (12), 3097-3104.

(116) Ouyang, F.; Pei, X.; Zhao, X.; Weng, H. Effect of operation conditions on the composition and octane number of gasoline in the process of reducing the content of olefins in fluid catalytic cracking (FCC) gasoline. Energy Fuels 2010, 24 (1), 475-482.

(117) Zhu, X.; Jiang, S.; Li, C.; Chen, X.; Yang, C. Residue catalytic cracking process for maximum ethylene and propylene production. Ind. Eng. Chem. Res. 2013, 52 (40), 14366-14375.

(118) Kim, S. W.; Lee, J. W.; Koh, J. S.; Kim, G. R.; Choi, S.; Yoo, I. S. Formation and characterization of deposits in cyclone dipleg of a commercial residue fluid catalytic cracking reactor. Ind. Eng. Chem. Res. 2012, 51 (43), 14279-14288.

(119) Güleç, F.; Meredith, W.; Sun, C.-G.; Snape, C. E. A novel approach to $\mathrm{CO}_{2}$ capture in Fluid Catalytic Cracking-Chemical Looping Combustion. Fuel 2019, 244, 140-150.

(120) Abrahamson, J. P.; Wincek, R. T.; Eser, S. Effects of catalyst properties on hydrodesulfurization activity for sulfur removal from fluid catalytic cracking decant oils. Energy Fuels 2016, 30 (9), 7173-7179.

(121) Chen, K.; Zhang, D.; Dai, Y.; Liu, H.; Wang, Z.; Ibrahim, U.-K.; Guo, A. Chemical and structural characterization of problematic 
suspended particles enriched from fluidized catalytic cracking slurry oil. Chem. Eng. Res. Des. 2019, 143, 36-46.

(122) Muddanna, M. H.; Baral, S. S. Leaching of Nickel and Vanadium from the spent fluid catalytic cracking catalyst by reconnoitering the potential of Aspergillus niger associating with chemical leaching. $J$. Environ. Chem. Eng. 2019, 7 (2), 103025.

(123) Yang, Z.; Cai, W.; Chou, J.; Cai, Z.; Jin, W.; Chen, J.; Xiong, Z.; $\mathrm{Ru}, \mathrm{X}$.; Xia, Q. Hydrothermal synthesis of plugged micro/mesoporous Al-SBA-15 from spent fluid catalytic cracking catalyst. Mater. Chem. Phys. 2019, 222, 227-229.

(124) Santillan-Jimenez, E.; Pace, R.; Morgan, T.; Behnke, C.; Sajkowski, D. J.; Lappas, A.; Crocker, M. Co-processing of hydrothermal liquefaction algal bio-oil and petroleum feedstock to fuel-like hydrocarbons via fluid catalytic cracking. Fuel Process. Technol. 2019, $188,164-171$.

(125) Ibarra, A. L.; Rodríguez, E.; Sedran, U.; Arandes, J. M.; Bilbao, J. Synergy in the cracking of a blend of bio-oil and vacuum gasoil under fluid catalytic cracking conditions. Ind. Eng. Chem. Res. 2016, 55 (7), $1872-1880$.

(126) Song, X.; Liu, D.; Lou, B.; Li, Z.; Guo, A.; Zhang, D.; Wang, L. Removal of catalyst particles from fluid catalytic cracking slurry oil by the simultaneous addition of a flocculants and a weighting agent. Chem. Eng. Res. Des. 2018, 132, 686-696.

(127) Otterstedt, J. E.; Gevert, S. B.; Jäås, S. G.; Menon, P. G. Fluid catalytic cracking of heavy (residual) oil fractions: a review. Appl. Catal. 1986, 22 (2), 159-179.

(128) Akah, A. Application of rare earths in fluid catalytic cracking: A review. J. Rare Earths 2017, 35 (10), 941-956.

(129) Lin, Y.; Wang, J.; Wang, H.; Gu, M.; Zhang, C.; Chu, H. Effects of $\mathrm{Fe}_{2} \mathrm{O}_{3}$ on pyrolysis characteristics of soybean protein and release of NOx precursors. Energy Sources, Part A 2018, 40 (4), 459-465.

(130) Uzi, A.; Shen, Y.; Kawi, S.; Levy, A.; Wang, C.-H. Permittivity and chemical characterization of woody biomass during pyrolysis and gasification. Chem. Eng. J. 2019, 355, 255-268.

(131) Dong, R.; Zhao, M. Research on the pyrolysis process of crumb tire rubber in waste cooking oil. Renewable Energy 2018, 125, 557-567.

(132) Liang, J.; Chen, J.; Wu, S.; Liu, C.; Lei, M. Comprehensive insights into cellulose structure evolution via multi-perspective analysis during a slow pyrolysis process. Sustainable Energy Fuels. 2018, 2 (8), $1855-1862$.

(133) Aylón, E.; Fernández-Colino, A.; Murillo, R.; Grasa, G.; Navarro, M. V.; García, T.; Mastral, A. M. Waste tyre pyrolysis: Modelling of a moving bed reactor. Waste Manage. 2010, 30 (12), 2530-2536.

(134) Aylón, E.; Fernández-Colino, A.; Navarro, M. V.; Murillo, R.; García, T.; Mastral, A. M. Waste tire pyrolysis: comparison between fixed bed reactor and moving bed reactor. Ind. Eng. Chem. Res. 2008, 47 (12), 4029-4033.

(135) Kodera, Y.; Ishihara, Y.; Kuroki, T. Novel process for recycling waste plastics to fuel gas using a moving-bed reactor. Energy Fuels 2006, 20 (1), 155-158.

(136) Gao, Y.; Wang, X.; Chen, Y.; Li, P.; Liu, H.; Chen, H. Pyrolysis of rapeseed stalk: Influence of temperature on product characteristics and economic costs. Energy 2017, 122, 482-491.

(137) Liang, P.; Zhang, Y.; Jiang, W.; Wei, A.; Liu, T.; Wu, J. Simulation study of Shenmu coal pyrolysis by gas heat carrier based on a moving bed. Energy Fuels 2015, 29 (11), 7727-7733.

(138) Yamaguchi, Y.; Fushimi, C.; Tasaka, K.; Furusawa, T.; Tsutsumi, A. Kinetic study on the pyrolysis of cellulose using the novel continuous cross-flow moving bed type differential reactor. Energy Fuels 2006, 20 (6), 2681-2685.

(139) Williams, P. T. Pyrolysis of waste tyres: a review. Waste Manage. 2013, 33 (8), 1714-1728.

(140) Wang, C.; Xu, S.; Wang, G.; Xiao, Y. Pyrolysis of coal hydroliquefaction residue in a dual loop reaction system. Fuel 2018, 212, 448-454.

(141) Zhang, Y.-Q.; Liang, P.; Yu, J.; Zhu, J.-L.; Qin, X.-Z. Studies of granular bed filter for dust removal in the process of coal pyrolysis by solid heat carrier. RSC Adv. 2017, 7 (33), 20266-20272.
(142) Aylón, E.; Fernández-Colino, A.; Murillo, R.; Navarro, M. V.; García, T.; Mastral, A. M. Valorisation of waste tyre by pyrolysis in a moving bed reactor. Waste Manage. 2010, 30 (7), 1220-1224.

(143) Kumar Singh, R.; Ruj, B.; Jana, A.; Mondal, S.; Jana, B.; Sadhukhan, A. K.; Gupta, P. Pyrolysis of three different categories of automotive tyre wastes: Product yield analysis and characterization. J. Anal. Appl. Pyrolysis 2018, 135, 379-389.

(144) Rudniak, L.; Machniewski, P. M. Modelling and experimental investigation of waste tyre pyrolysis process in a laboratory reactor. Chem. Process. Eng. 2017, 38 (3), 445-454.

(145) Lai, D.; Chen, Z.; Shi, Y.; Lin, L.; Zhan, J.; Gao, S.; Xu, G. Pyrolysis of oil shale by solid heat carrier in an innovative moving bed with internals. Fuel 2015, 159, 943-951.

(146) Lai, D.; Shi, Y.; Geng, S.; Chen, Z.; Gao, S.; Zhan, J.-H.; Xu, G. Secondary reactions in oil shale pyrolysis by solid heat carrier in a moving bed with internals. Fuel 2016, 173, 138-145.

(147) Lai, D.; Zhang, G.; Xu, G. Characterization of oil shale pyrolysis by solid heat carrier in moving bed with internals. Fuel Process. Technol. 2017, 158, 191-198.

(148) Zhang, X.; Che, Q.; Cui, X.; Wei, Z.; Zhang, X.; Chen, Y.; Wang, $\mathrm{X}$.; Chen, H. Application of biomass pyrolytic polygeneration by a moving bed: Characteristics of products and energy efficiency analysis. Bioresour. Technol. 2018, 254, 130-138.

(149) Zhu, J.; Yang, Y.; Yang, L.; Zhu, Y. High quality syngas produced from the co-pyrolysis of wet sewage sludge with sawdust. Int. J. Hydrogen Energy 2018, 43 (11), 5463-5472.

(150) Yang, Y.; Zhu, J.; Zhu, G.; Yang, L.; Zhu, Y. The effect of high temperature on syngas production by immediate pyrolysis of wet sewage sludge with sawdust. J. Therm. Anal. Calorim. 2018, 132 (3), $1783-1794$.

(151) Zhu, J.; Wan, L.; Chen, H.; Zhu, Y.; Yang, L. Pilot test of copyrolysis characteristics of wet sewage sludge and sawdust in an external heating moving bed. Energy Procedia 2017, 105, 570-575.

(152) Adnan, M. A.; Susanto, H.; Binous, H.; Muraza, O.; Hossain, M. M. Enhancement of hydrogen production in a modified moving bed downdraft gasifier-A thermodynamic study by including tar. Int. J. Hydrogen Energy 2017, 42 (16), 10971-10985.

(153) Denn, M. M.; Yu, W.-C.; Wei, J. Parameter sensitivity and kinetics-free modeling of moving bed coal gasifiers. Ind. Eng. Chem. Fundam. 1979, 18 (3), 286-288.

(154) Amundson, N. R.; Arri, L. E. Char gasification in a countercurrent reactor. AIChE J. 1978, 24 (1), 87-101.

(155) Ahmadlou, M.; Rezakazemi, M. Computational fluid dynamics simulation of moving-bed nanocatalytic cracking process for the lightening of heavy crude oil. J. Porous Media 2018, 21 (6), 539.

(156) Yang, W. J.; Zhou, Z. Y.; Yu, A. B. Particle scale studies of heat transfer in a moving bed. Powder Technol. 2015, 281, 99-111.

(157) Adanez, J.; Labiano, F. G. Modeling of moving-bed coal gasifiers. Ind. Eng. Chem. Res. 1990, 29 (10), 2079-2088.

(158) Chiang, C.-L.; Fang, Z.-R. Simulation and optimal design for the residual oil hydrodemetallation in a cocurrent moving-bed reactor. Chem. Eng. Sci. 1994, 49 (8), 1175-1183.

(159) Bijani, P. M.; Sahebdelfar, S. Modeling of a radial-flow movingbed reactor for dehydrogenation of isobutane. Kinet. Catal. 2008, 49 (4), 599-605.

(160) Mu, Z.; Wang, J.; Wang, T.; Jin, Y. Optimum design of radial flow moving-bed reactors based on a mathematical hydrodynamic model. Chem. Eng. Process. 2003, 42 (5), 409-417.

(161) Szwast, Z.; Sieniutycz, S. Optimal dynamical processes in tubular reactor with deactivation of multi-run moving catalyst. Chem. Eng. J. 2004, 103 (1-3), 45-50.

(162) Tórrez, N.; Gustafsson, M.; Schreil, A.; Martínez, J. Modeling and simulation of crossflow moving bed grain dryers. Drying Technol. 1998, 16 (9-10), 1999-2015.

(163) Golman, B.; Shinohara, K. Optimal operation of moving-bed reactor for CVD coating of fine particles. Chem. Eng. Res. Des. 1999, 77 (1), 39-46. 
(164) Pang, S.; Xu, Q. Drying of woody biomass for bioenergy using packed moving bed dryer: Mathematical modeling and optimization. Drying Technol. 2010, 28 (5), 702-709.

(165) Sahebdelfar, S.; Bijani, P. M.; Saeedizad, M.; Zangeneh, F. T.; Ganji, K. Modeling of adiabatic moving-bed reactor for dehydrogenation of isobutane to isobutene. Appl. Catal., A 2011, 395 (1-2), 107113.

(166) Shao, Y.; Zhang, Y.; Wang, X.; Wang, X.; Jin, B.; Liu, H. Threedimensional full loop modeling and optimization of an in situ gasification chemical looping combustion system. Energy Fuels 2017, 31 (12), 13859-13870.

(167) Yang, M. Computational fluid dynamics modeling and simulations of fast fluidized bed and moving bed reactors for chemical looping combustion. Master of Science, Washington University, St. Louis, 2017.

(168) Kathe, M. V.; Empfield, A.; Na, J.; Blair, E.; Fan, L.-S. Hydrogen production from natural gas using an iron-based chemical looping technology: Thermodynamic simulations and process system analysis. Appl. Energy 2016, 165, 183-201.

(169) Karim, M. R.; Naser, J. CFD modelling of combustion and associated emission of wet woody biomass in a $4 \mathrm{MW}$ moving grate boiler. Fuel 2018, 222, 656-674.

(170) Baruah, D.; Baruah, D. C.; Hazarika, M. K. Artificial neural network based modeling of biomass gasification in fixed bed downdraft gasifiers. Biomass Bioenergy 2017, 98, 264-271.

(171) Tsubaki, J.; Tien, C. Solid velocity in cross-flow moving beds. Powder Technol. 1987, 53 (2), 105-112.

(172) Arabi, S.; Rafsanjani, H. H. Modeling and simulation of noncatalytic gas-solid reaction in a moving bed reactor. Chem. Prod. Process Model. 2008, 3 (1), 1-29.

(173) Gupta, P.; Velazquez-Vargas, L. G.; Valentine, C.; Fan, L.-S. Moving bed reactor setup to study complex gas-solid reactions. Rev. Sci. Instrum. 2007, 78 (8), 085106.

(174) Kim, H.; Miller, D. C.; Modekurti, S.; Omell, B.; Bhattacharyya, D.; Zitney, S. E. Mathematical modeling of a moving bed reactor for post combustion $\mathrm{CO}_{2}$ capture. AIChE J. 2016, 62 (11), 3899-3914.

(175) Munro, W. D.; Amundson, N. R. Solid-fluid heat exchange in moving beds. Ind. Eng. Chem. 1950, 42 (8), 1481-1488.

(176) Siegmund, C. W.; Munro, W. D.; Amundson, N. R. Two problems on moving beds. Ind. Eng. Chem. 1956, 48 (1), 43-50.

(177) Parisi, D. R.; Laborde, M. A. Modeling of counter current moving bed gas-solid reactor used in direct reduction of iron ore. Chem. Eng. J. 2004, 104 (1-3), 35-43.

(178) El-Hedok, I. A.; Whitmer, L.; Brown, R. C. The influence of granular flow rate on the performance of a moving bed granular filter. Powder Technol. 2011, 214 (1), 69-76.

(179) Hsu, C.-J.; Hsiau, S.-S. A study of filtration performance in a cross-flow moving granular bed filter: the influence of gas flow uniformity. Powder Technol. 2015, 274, 20-27.

(180) Paenpong, C.; Pattiya, A. Filtration of fast pyrolysis char fines with a cross-flow moving-bed granular filter. Powder Technol. 2013, 245, 233-240.

(181) Smid, J.; Hsiau, S. S.; Peng, C. Y.; Lee, H. T. Hot gas cleanup: pilot testing of moving bed filters. Filtr. Sep. 2006, 43 (4), 21-24.

(182) Marban, G.; Fuertes, A. B. A simple method for studying the kinetics of gas-solid reactions in a fluidized bed reactor. Chem. Eng. Commun. 1994, 130 (1), 241-250.

(183) Pinheiro, C. I.; Fernandes, J. L.; Domingues, L.; Chambel, A. J.; Graca, I.; Oliveira, N. M.; Cerqueira, H. S.; Ribeiro, F. R. Fluid catalytic cracking (FCC) process modeling, simulation, and control. Ind. Eng. Chem. Res. 2012, 51 (1), 1-29.

(184) Cristina, P. Four-lump kinetic model vs. three-lump kinetic model for the fluid catalytic cracking riser reactor. Procedia Eng. 2015, 100, 602-608.

(185) Sani, A. G.; Ebrahim, H. A.; Azarhoosh, M. J. 8-Lump kinetic model for fluid catalytic cracking with olefin detailed distribution study. Fuel 2018, 225, 322-335.
(186) Li, Y.; Chu, J.; Zhang, J. A new generic reaction for modeling fluid catalytic cracking risers. Chin. J. Chem. Eng. 2017, 25 (10), 14491460.

(187) John, Y. M.; Mustafa, M. A.; Patel, R.; Mujtaba, I. M. Parameter estimation of a six-lump kinetic model of an industrial fluid catalytic cracking unit. Fuel 2019, 235, 1436-1454.

(188) Kalra, L.; Georgakis, C. Effect of process nonlinearity on the performance of linear model predictive controllers for the environmentally safe operation of a fluid catalytic cracking unit. Ind. Eng. Chem. Res. 1994, 33 (12), 3063-3069.

(189) Fernandes, J. L.; Pinheiro, C. I.; Oliveira, N. M.; Inverno, J.; Ribeiro, F. R. Model development and validation of an industrial UOP fluid catalytic cracking unit with a high-efficiency regenerator. Ind. Eng. Chem. Res. 2008, 47 (3), 850-866.

(190) Shah, M. T.; Pareek, V. K.; Evans, G. M.; Utikar, R. P. Effect of baffles on performance of fluid catalytic cracking riser. Particuology 2018, 38, 18-30.

(191) Veluswamy, G. K.; Upadhyay, R. K.; Utikar, R. P.; Tade, M. O.; Evans, G.; Glenny, M. E.; Roy, S.; Pareek, V. K. Hydrodynamic study of fluid catalytic cracker unit stripper. Ind. Eng. Chem. Res. 2013, 52 (12), $4660-4671$

(192) Zhang, Y.; Lu, C. Experimental study and modeling on effects of a new multilayer baffle in a turbulent fluid catalytic cracking regenerator. Ind. Eng. Chem. Res. 2014, 53 (5), 2062-2066.

(193) Jarullah, A. T.; Awad, N. A.; Mujtaba, I. M. Optimal design and operation of an industrial fluidized catalytic cracking reactor. Fuel 2017, 206, 657-674.

(194) Guan, H.; Ye, L.; Shen, F.; Song, Z. Economic operation of a fluid catalytic cracking process using self-optimizing control and reconfiguration. J. Taiwan Inst. Chem. Eng. 2019, 96, 104-113.

(195) Sheng, Q.; Wang, G.; Liu, Y.; Husein, M. M.; Gao, C.; Shi, Q.; Gao, J. Combined Hydrotreating and Fluid Catalytic Cracking Processing for the Conversion of Inferior Coker Gas Oil: Effect on Nitrogen Compounds and Condensed Aromatics. Energy Fuels 2018, 32 (4), 4979-4987.

(196) Odjo, A. O.; García, A. N.; Marcilla, A. Conversion of low density polyethylene into fuel through co-processing with vacuum gas oil in a fluid catalytic cracking riser reactor. Fuel Process. Technol. 2013, $113,130-140$.

(197) Alexiadis, V. I.; Heuchel, M.; Traa, Y.; Klemm, E.; Papayannakos, N.; Thybaut, J. W. Model based analysis of the effect of 2-ethylphenol addition to n-decane in fluid catalytic cracking over a series of zeolites. Chem. Eng. J. 2018, in press. DOI: 10.1016/ j.cej.2018.10.027

(198) Gyngazova, M. S.; Kravtsov, A. V.; Ivanchina, E. D.; Korolenko, M. V.; Chekantsev, N. V. Reactor modeling and simulation of movingbed catalytic reforming process. Chem. Eng. J. 2011, 176, 134-143.

(199) Kaufmann, T. G.; Kaldor, A.; Stuntz, G. F.; Kerby, M. C.; Ansell, L. L. Catalysis science and technology for cleaner transportation fuels. Catal. Today 2000, 62 (1), 77-90.

(200) Weyda, H.; Köhler, E. Modern refining concepts-an update on naphtha-isomerization to modern gasoline manufacture. Catal. Today 2003, 81 (1), 51-55.

(201) Aitani, A. M. Catalytic naphtha reforming. In Encyclopedia of Chemical Processing; Lee, S., Ed.; Taylor \& Francis Group: Boca Raton, 2006; Vol. 1, pp 397-406.

(202) Mata, T. M.; Smith, R. L.; Young, D. M.; Costa, C. A. V. Environmental analysis of gasoline blending components through their life cycle. J. Cleaner Prod. 2005, 13 (5), 517-523.

(203) Ancheyta-Juarez, J.; Villafuerte-Macias, E. Kinetic modeling of naphtha catalytic reforming reactions. Energy Fuels 2000, 14 (5), 10321037.

(204) Wang, P.; Shen, B.; Shen, D.; Peng, T.; Gao, J. Synthesis of ZSM-5 zeolite from expanded perlite/kaolin and its catalytic performance for FCC naphtha aromatization. Catal. Commun. 2007, 8 (10), $1452-1456$

(205) Ramos, M. J.; Gomez, J. P.; Dorado, F.; Sánchez, P.; Valverde, J. L. Hydroisomerization of a refinery naphtha stream over platinum zeolite-based catalysts. Chem. Eng. J. 2007, 126 (1), 13-21. 
(206) Mohanty, S.; Kunzru, D.; Saraf, D. N. Hydrocracking: a review. Fuel 1990, 69 (12), 1467-1473.

(207) Rodríguez, M. A.; Ancheyta, J. Detailed description of kinetic and reactor modeling for naphtha catalytic reforming. Fuel 2011, 90 (12), 3492-3508.

(208) Taskar, U.; Riggs, J. B. Modeling and optimization of a semiregenerative catalytic naphtha reformer. AIChE J. 1997, 43 (3), 740-753.

(209) Ancheyta, J.; Villafuerte, E.; Schachat, P.; Aguilar, R.; Gonzalez, E. Simulation of a commercial semiregenerative reforming plant using feedstocks with and without benzene precursors. Chem. Eng. Technol. 2002, 25 (5), 541-546.

(210) Stell, J. 2000 Worldwide refining survey. Oil Gas J. 2000, 98 (51), 66-120.

(211) Pollitzer, E. L.; Haensel, V.; Hayes, J. C. In New Developments in Reforming. Conference Paper WPC-14329, 8th World Petroleum Congress, June 13-18, 1971; World Petroleum Congress: Moscow, USSR, 1971.

(212) Abdel-Gawad, A. K.; Ashour, H.; Zakzouk, E. E. Partial Modification for System Enhancement of the Continuous Catalyst Regeneration system. Proceedings of the IEEE International Conference on Control Applications. 2003, 1, 742-747.

(213) Elizalde, I.; Ancheyta, J. Dynamic modeling and simulation of a naphtha catalytic reforming reactor. Appl. Math. Modell. 2015, 39 (2), 764-775.

(214) Froment, G. F. Modeling of catalyst deactivation. Appl. Catal., A 2001, 212 (1-2), 117-128.

(215) Sie, S. T. Consequences of catalyst deactivation for process design and operation. Appl. Catal., A 2001, 212 (1-2), 129-151.

(216) Sie, S. T. Catalyst Deactivation by Poisoning and Pore Plugging in Petroleum Processing. In Stud. Surf. Sci. Catal.; Delmon, B., Froment, G. F., Eds.; Elsevier: Amsterdam, 1980; Vol. 6, pp 545-569.

(217) Baghalha, M.; Mohammadi, M.; Ghorbanpour, A. Coke deposition mechanism on the pores of a commercial Pt- $\mathrm{Re} / \gamma-\mathrm{Al}_{2} \mathrm{O}_{3}$ naphtha reforming catalyst. Fuel Process. Technol. 2010, 91 (7), 714722.

(218) Froment, G. F. Kinetic modeling of hydrocarbon processing and the effect of catalyst deactivation by coke formation. Catal. Rev.: Sci. Eng. 2008, 50 (1), 1-18.

(219) Verderone, R. J.; Pieck, C. L.; Sad, M. R.; Parera, J. M. Influence of chlorine content on the behavior of Pt- $\mathrm{Re} / \mathrm{Al}_{2} \mathrm{O}_{3}$ catalyst for naphtha reforming. Appl. Catal. 1986, 21 (2), 239-250.

(220) Khosravanipour Mostafazadeh, A.; Rahimpour, M. R. A membrane catalytic bed concept for naphtha reforming in the presence of catalyst deactivation. Chem. Eng. Process. 2009, 48 (2), 683-694.

(221) Monzón, A.; Romeo, E.; Borgna, A. Relationship between the kinetic parameters of different catalyst deactivation models. Chem. Eng. J. 2003, 94 (1), 19-28.

(222) Corella, J.; Adanez, J.; Monzon, A. Some intrinsic kinetic equations and deactivation mechanisms leading to deactivation curves with a residual activity. Ind. Eng. Chem. Res. 1988, 27 (3), 375-381.

(223) Hu, Y.; Su, H.; Chu, J. Modeling, simulation and optimization of commercial naphtha catalytic reforming process. In 42nd IEEE International Conference on Decision and Control (IEEE Catal. No.03CH37475). 2003, 6, 6206-6211.

(224) Pujadó, P. R.; Moser, M., Catalytic reforming. In Handbook of Petroleum Processing; Jones, D. S. J. S, Pujadó, P. R., Eds.; Springer: Dordrecht, 2008; pp 217-237.

(225) Stijepovic, V.; Linke, P.; Alnouri, S.; Kijevcanin, M.; Grujic, A.; Stijepovic, M. Toward enhanced hydrogen production in a catalytic naphtha reforming process. Int. J. Hydrogen Energy 2012, 37 (16), $11772-11784$.

(226) Smith, R. B. Kinetic analysis of naphtha reforming with platinum catalyst. Chem. Eng. Prog. 1959, 55 (6), 76-80.

(227) Krane, H. G.; Groh, A. B.; Schulman, B. L.; Sinfelt, J. H. In 4 Reactions in catalytic reforming of naphthas, Document ID WPC-8204, 5th World Petroleum Congress, May 30-June 5; World Petroleum Congress: New York, 1959.
(228) Iranshahi, D.; Karimi, M.; Amiri, S.; Jafari, M.; Rafiei, R.; Rahimpour, M. R. Modeling of naphtha reforming unit applying detailed description of kinetic in continuous catalytic regeneration process. Chem. Eng. Res. Des. 2014, 92 (9), 1704-1727.

(229) Ramage, M. P.; Graziani, K. R.; Krambeck, F. J. 6 Development of mobil's kinetic reforming model. Chem. Eng. Sci. 1980, 35 (1-2), $41-48$.

(230) Stijepovic, M. Z.; Vojvodic-Ostojic, A.; Milenkovic, I.; Linke, P. Development of a kinetic model for catalytic reforming of naphtha and parameter estimation using industrial plant data. Energy Fuels 2009, 23 (2), 979-983.

(231) Froment, G. F. The kinetics of complex catalytic reactions. Chem. Eng. Sci. 1987, 42 (5), 1073-1087.

(232) Sedighi, M.; Keyvanloo, K.; Towfighi, J. Kinetic study of steam catalytic cracking of naphtha on a Fe/ZSM-5 catalyst. Fuel 2013, 109, 432-438.

(233) Ancheyta-Juarez, J.; Villafuerte-Macias, E.; Diaz-Garcia, L.; Gonzalez-Arredondo, E. Modeling and simulation of four catalytic reactors in series for naphtha reforming. Energy Fuels 2001, 15 (4), $887-893$.

(234) Sotelo-Boyás, R.; Froment, G. F. Fundamental kinetic modeling of catalytic reforming. Ind. Eng. Chem. Res. 2009, 48 (3), 1107-1119.

(235) Fazeli, A.; Fatemi, S.; Mahdavian, M.; Ghaee, A. Mathematical modeling of an industrial naphtha reformer with three adiabatic reactors in series. Iran. J. Chem. Chem. Eng. 2009, 28 (3), 97-102.

(236) Bommannan, D.; Srivastava, R. D.; Saraf, D. N. Modelling of catalytic naphtha reformers. Can. J. Chem. Eng. 1989, 67 (3), 405-411.

(237) Lee, J. W.; Ko, Y. C.; Jung, Y. K.; Lee, K. S.; Yoon, E. S. A modeling and simulation study on a naphtha reforming unit with a catalyst circulation and regeneration system. Comput. Chem. Eng. 1997, 21, S1105-S1110.

(238) Wei, M.; Yang, M.; Qian, F.; Du, W.; He, W.; Zhong, W. Dynamic modeling and economic model predictive control with production mode switching for an industrial catalytic naphtha reforming process. Ind. Eng. Chem. Res. 2017, 56 (31), 8961-8971.

(239) Pashikanti, K.; Liu, Y. Predictive modeling of large-scale integrated refinery reaction and fractionation systems from plant data. Part 3: Continuous catalyst regeneration (CCR) reforming process. Energy Fuels 2011, 25 (11), 5320-5344.

(240) Bishara, A.; Stanislaus, A.; Hussain, S. S. Effect of feed composition and operating conditions on catalyst deactivation and on product yield and quality during naphtha catalytic reforming. Appl. Catal. 1984, 13 (1), 113-125.

(241) Figoli, N. S.; Beltramini, J. N.; Marinelli, E. E.; Sad, M. R.; Parera, J. M. Operational conditions and coke formation on $\mathrm{Pt}_{-} \mathrm{Al}_{2} \mathrm{O}_{3}$ reforming catalyst. Appl. Catal. 1983, 5 (1), 19-32.

(242) Lid, T.; Skogestad, S. Data reconciliation and optimal operation of a catalytic naphtha reformer. J. Process Control 2008, 18 (3-4), 320331.

(243) Shakoor, Z. M. Catalytic reforming of heavy naphtha, analysis and simulation. Diyala J. Eng. Sci. 2011, 4 (2), 86-104.

(244) Hongjun, Z.; Mingliang, S.; Huixin, W.; Zeji, L.; Hongbo, J. Modeling and simulation of moving bed reactor for catalytic naphtha reforming. Pet. Sci. Technol. 2010, 28 (7), 667-676.

(245) Karimi, M.; Rahimpour, M. R.; Rafiei, R.; Shariati, A.; Iranshahi, $D$. Improving thermal efficiency and increasing production rate in the double moving beds thermally coupled reactors by using differential evolution (DE) technique. Appl. Therm. Eng. 2016, 94, 543-558.

(246) Dautzenberg, F. M.; Mukherjee, M. Process intensification using multifunctional reactors. Chem. Eng. Sci. 2001, 56 (2), 251-267.

(247) Karimi, M.; Rahimpour, M. R.; Iranshahi, D. Enhanced BTX production in refineries with sulfur dioxide oxidation by thermal integrated model. Chem. Eng. Technol. 2018, 41 (9), 1746-1758.

(248) Rahimpour, M. R.; Iranshahi, D.; Paymooni, K.; Pourazadi, E. Enhancement in research octane number and hydrogen production via dynamic optimization of a novel spherical axial-flow membrane naphtha reformer. Ind. Eng. Chem. Res. 2012, 51 (1), 398-409.

(249) Velázquez, D.; González-Falcón, R.; Pérez-Lombard, L.; Gallego, L. M.; Monedero, I.; Biscarri, F. Development of an energy 
management system for a naphtha reforming plant: A data mining approach. Energy Convers. Manage. 2013, 67, 217-225.

(250) Babaqi, B. S.; Takriff, M. S.; Kamarudin, S. K.; Othman, N. T. A.; Ba-Abbad, M. M. Energy optimization for maximum energy saving with optimal modification in Continuous Catalytic Regeneration Reformer Process. Energy 2017, 120, 774-784.

(251) Iranshahi, D.; Rafiei, R.; Jafari, M.; Amiri, S.; Karimi, M.; Rahimpour, M. R. Applying new kinetic and deactivation models in simulation of a novel thermally coupled reactor in continuous catalytic regenerative naphtha process. Chem. Eng. J. 2013, 229, 153-176.

(252) Jafari, M.; Rafiei, R.; Amiri, S.; Karimi, M.; Iranshahi, D.; Rahimpour, M. R.; Mahdiyar, H. Combining continuous catalytic regenerative naphtha reformer with thermally coupled concept for improving the process yield. Int. J. Hydrogen Energy 2013, 38 (25), 10327-10344.

(253) Karimi, M.; Rahimpour, M. R.; Rafiei, R.; Jafari, M.; Iranshahi, D.; Shariati, A. Reducing environmental problems and increasing saving energy by proposing new configuration for moving bed thermally coupled reactors. J. Nat. Gas Sci. Eng. 2014, 17, 136-150.

(254) Iranshahi, D.; Saeedi, R.; Azizi, K.; Nategh, M. A novel integrated thermally coupled moving bed reactors for naphtha reforming process with hydrodealkylation of toluene. Appl. Therm. Eng. 2017, 112, 1040-1056.

(255) Saeedi, R.; Iranshahi, D. Multi-objective optimization of thermally coupled reactor of CCR naphtha reforming in presence of $\mathrm{SO}_{2}$ oxidation to boost the gasoline octane number and hydrogen. Fuel 2017, 206, 580-592.

(256) Iranshahi, D.; Hamedi, N.; Nategh, M.; Saeedi, R.; Saeidi, S. Thermal integration of sulfuric acid and continuous catalyst regeneration of naphtha reforming plants. Chem. Eng. Technol. 2018, 41 (3), 637-655.

(257) Iranshahi, D.; Amiri, S.; Karimi, M.; Rafiei, R.; Jafari, M.; Rahimpour, M. R. Modeling and simulation of a novel membrane reactor in a continuous catalytic regenerative naphtha reformer accompanied with a detailed description of kinetics. Energy Fuels 2013, 27 (7), 4048-4070.

(258) Saeedi, R.; Iranshahi, D. Hydrogen and aromatic production by means of a novel membrane integrated cross flow CCR naphtha reforming process. Int. J. Hydrogen Energy 2017, 42 (12), 7957-7973.

(259) Iranshahi, D.; Jafari, M.; Rafiei, R.; Karimi, M.; Amiri, S.; Rahimpour, M. R. Optimal design of a radial-flow membrane reactor as a novel configuration for continuous catalytic regenerative naphtha reforming process considering a detailed kinetic model. Int. J. Hydrogen Energy 2013, 38 (20), 8384-8399.

(260) Turaga, U. T.; Ramanathan, R. Catalytic naphtha reforming: revisiting its importance in the modern refinery. J. Sci. Ind. Res. 2003, 62 (10), 963-978.

(261) Hu, S.; Zhu, X. X. Molecular modeling and optimization for catalytic reforming. Chem. Eng. Commun. 2004, 191 (4), 500-512.

(262) Heinemann, H. The dynamics of innovations and development in catalyst based technologies. Catalytic reforming, cracking, and ammonia production. Catal. Lett. 1988, 1 (12), 413-421.

(263) Rahimpour, M. R.; Iranshahi, D.; Pourazadi, E.; Paymooni, K.; Bahmanpour, A. M. The aromatic enhancement in the axial flow spherical packed bed membrane naphtha reformers in the presence of catalyst deactivation. AIChE J. 2011, 57 (11), 3182-3198. 